\title{
Magnesium adsorption and ion exchange in marine sediments: A multi-component model
}

\author{
MARTA T. von BReymanN, ${ }^{1}$ Robert COLlier, ${ }^{2}$ and ERwin Suess ${ }^{2,3}$ \\ 'Ocean Drilling Program, Texas A\&M University, College Station, TX 77840, USA \\ ${ }^{2}$ College of Oceanography, Oregon State University, Corvallis, OR 97331, USA \\ ${ }^{3}$ GEOMAR Research Center, D-23 Kiel 14, Germany
}

(Received November 22, 1988; accepted in revised form August 21, 1990)

\begin{abstract}
The observed distribution of dissolved magnesium in the pore water of rapidly accumulating sediments shows significant deviations from the seawater value. We have shown that deviations during early diagenesis can be explained by reactions occurring at the surface of sediment particles.

In anoxic pore water environments with high levels of dissolved total carbon dioxide the formation of $\mathrm{Mg}^{+2} \cdot \mathrm{CO}_{3}^{-2}$ complexes significantly reduces the concentration of the free $\mathrm{Mg}^{+2}$ ion. This decrease in the $\mathrm{Mg}^{+2}$ activity results in desorption of magnesium from the solid surfaces due to the re-equilibration of the adsorbed $\mathrm{Mg}^{+2}$ with the dissolved species. The effect of increasing carbonate complexation of $\mathrm{Mg}^{+2}$ in anoxic environments is initially compensated by the loss of sulfate, which is also a strong $\mathrm{Mg}^{+2}$ ligand. Therefore, significant changes in free $\mathrm{Mg}^{+2}$ concentration and thus in the magnesium desorption from solid surfaces by ligand competition for $\mathrm{Mg}^{+2}$ are more pronounced in sulfate-depleted systems undergoing methanogenesis. Such conditions are characteristic of most continental margin sediments.

Another consequence of the decomposition of organic matter in hemipelagic sediments is the accumulation of high levels of ammonium ions which also displace $\mathrm{Mg}^{+2}$ from sediment-particle surfaces by ion exchange. These equilibria in the pore water-sediment systems can be described by empirical parameters, which were experimentally obtained. A computer model was used to determine the equilibrium conditions for solid-solution reactions as a function of changes in the pore-water composition in organicrich hemipelagic environments. This model includes complex formation, competition for $\mathrm{Mg}^{+2}$ between dissolved ligands and exchange sites, and $\mathrm{Mg}^{+2} / \mathrm{NH}_{4}^{+}$exchange reactions. The relative proportion of desorbed and displaced $\mathrm{Mg}^{+2}$ from the solid surface depends on the characteristics of the sediment and on the $\mathrm{\Sigma CO}_{2}: \mathrm{NH}_{4}^{+}$regenerative ratio in the pore waters.

In sediments from Bransfield Strait, the Gulf of California, and the Peru margin, both release mechanisms for $\mathrm{Mg}^{+2}$-ligand competition and ion exchange with ammonium-were evaluated as part of the complex reaction system in order to explain the observed maxima in the dissolved magnesium profiles. Overlying the $\mathrm{Mg}^{+2}$ maxima, the Bransfield Strait and Gulf of California pore waters show minima in the dissolved magnesium concentration, concurrent with a measured increase in the cation exchange capacity (CEC) of the sediments. By including the observed CEC changes in the multi-component model we show that the negative anomaly in the dissolved $\mathrm{Mg}^{+2}$ profiles is a consequence of changes in the CEC of sediments during the very early stages of anoxic diagenesis.
\end{abstract}

\section{INTRODUCTION}

PORE WATERS OF CONTINENTAL margin sediments show significant deviations in the dissolved $\mathrm{Mg}^{+2}$ concentrations relative to the seawater values. Depletions in the dissolved $\mathrm{Mg}^{+2}$ of pore water during early diagenesis have been reported from various marine environments. DREVER (1971a,b) observed $\mathrm{Mg}^{+2}$ removal from the anoxic interstitial waters of Banderas Bay, Mexico. He suggested that the uptake was the result of $\mathrm{Mg}$-for-Fe replacement in the non-exchangeable positions of clay minerals. SHOLKOVITZ (1973) observed similar depletions of interstitial dissolved $\mathrm{Mg}^{+2}$ in the sediments of Santa Barbara basin and, on the basis of an alkalinity model, concluded that the $\mathrm{Mg}^{+2}$ removal was due to a diagenetic increase in the cation uptake capacity of the clay minerals. Below the zone of $\mathrm{Mg}^{+2}$ depletion, pore water profiles at various DSDP and ODP sites show maxima in the dissolved concentration of this cation. GIESKES et al. (1982), MOORE and GIESKES (1980), COOK (1974), and SUESS et al. (1987) have attributed these maxima to release of magnesium by ammonium exchange.

Our objective is to determine the mechanisms leading to the observed $\mathrm{Mg}^{+2}$ minima and maxima in the pore water profiles. For this purpose we have previously determined conditional equilibrium constants for the $\mathrm{Mg}^{+2}-\mathrm{NH}_{4}^{+}$exchange reactions involving bulk sediments and several geochemical phases equilibrated in a seawater matrix (VON BREYMANN and SUESS, 1988). However, before empirical constants can be applied to model the sediment-pore water systems, we must evaluate the effect that a deviation of the pore water composition from seawater would have on the speciation of magnesium.

Although in any electrolyte solution there is continual interaction of ions, in seawater and pore waters the high ionic strength and increase in the interaction potential between ions lead to the formation of particularly stable association complexes. The extent of these ion-associations significantly affects the overall solution properties, since chemical equilibria, including adsorption and ion exchange, depend on the fraction of free ionic species (i.e., activity), rather than on the total concentration of a component.

Extensive work has been done with models of multi-ionic interaction in seawater (GARRELS and THOMSON, 1962; Millero, 1974; Millero and SCHREIBER, 1982). The con- 
centrations of $\mathrm{NH}_{4}^{+}, \mathrm{SO}_{4}^{-2}$, and $\mathrm{CO}_{3}^{-2}$ in interstitial waters, however, deviate considerably from the composition of the overlying seawater. Interstitial waters at Site 479 in the Gulf of California (GIESKES et al., 1982) are depleted in sulfate and strongly enriched in $\Sigma \mathrm{CO}_{2}$ (alkalinity $=75 \mathrm{mM}$ ) and ammonium (20 mM). MURRAY et al. ( 1978) and MARTENS et al. (1978) have reported alkalinity levels as high as $50 \mathrm{mM}$ from pore waters in Saanich Inlet and Long Island Sound sediments. WHITICAR (1978) has measured alkalinities greater than $100 \mathrm{mM}$ in Baltic Sea sediments, and SUESS et al. (1982) have reported values greater than $60 \mathrm{mM}$ in Bransfield Strait sediments. Pore fluid samples recovered from Peru margin sediments during ODP Leg 112 showed alkalinities as high as $200 \mathrm{mM}$ and ammonium concentrations reaching $>60 \mathrm{mM}$ (SUESS et al., 1988). Such high levels of dissolved carbonate in sulfate-devoid environments have a major effect on the speciation of $\mathrm{Ca}^{+2}$ and $\mathrm{Mg}^{+2}$ in the pore waters, since both cations form strong complexes with $\mathrm{CO}_{3}^{-2}$ and $\mathrm{SO}_{4}^{-2}$ anions (MILlero, 1974; PYTKOWICZ and HAWLEY, 1974; KeSTNER and PYTKOWICZ, 1969). Changes in the free $\mathrm{Mg}^{+2}$ concentration, due to sediment diagenesis, will result in a re-equilibration of the adsorbed $\mathrm{Mg}^{+2}$ relative to the dissolved species. This re-adjustment involves a transfer of magnesium from the solid to the dissolved reservoir and therefore plays a signiticant role in shaping the total $\mathrm{Mg}^{+2}$ transport.

Nutrient regeneration by organic matter decomposition has often been described by reactions based on the classical models of REDFIELD et al. (1963) and RICHARDS (1965). However, the relative metabolite concentration in interstitial waters of strongly anoxic sediments deviates from those predicted by the stoichiometric models (SUESS, 1976). These deviations have been attributed to changes in the organic matter substrate, preferential removal of organic nitrogen and organic phosphorous relative to organic carbon during decomposition (HARTMANN et al., 1973; BALZER, 1984), ad-

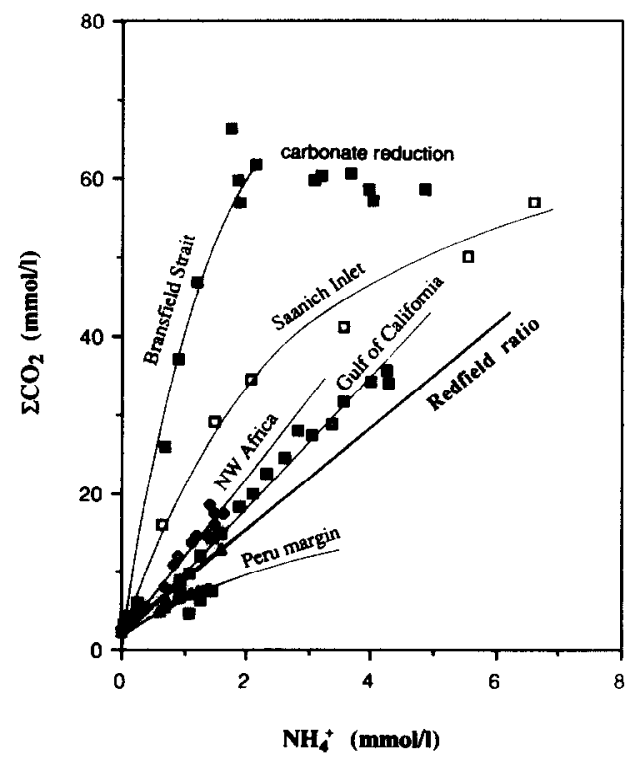

FIG. 1. Dissolved total carbon dioxide versus ammonia in the pore water of several hemipelagic sediments.

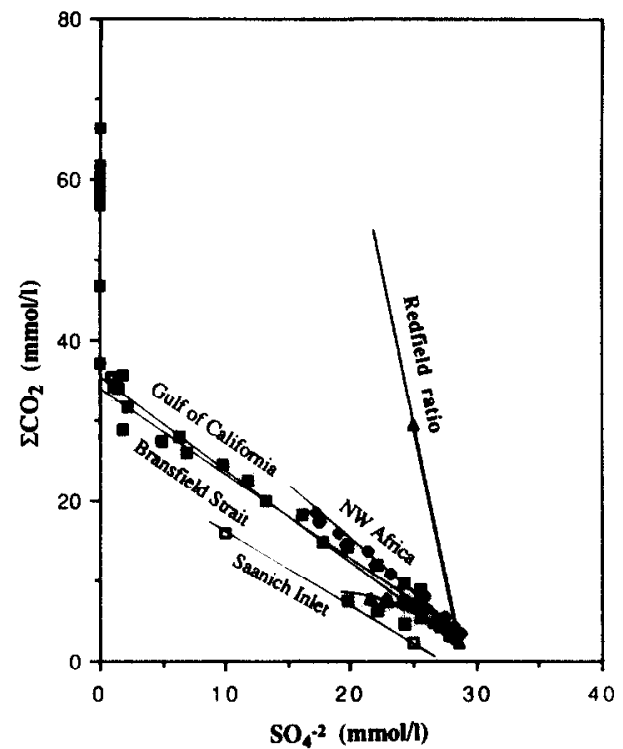

FIG. 2. Dissolved total carbon dioxide versus sulfate in the pore water of several hemipelagic sediments.

ditional release of phosphate from inorganic sources (SuESS, 1981 ), and preferential nitrogen uptake by nitrification and denitrification reactions within the sediments (BALZER, 1984). Furthermore, during advanced diagenesis in strongly anoxic settings, $\mathrm{\Sigma CO}_{2}$ may be removed by microbial methane formation (WHITICAR et al., 1986) and by the precipitation of authigenic solid phases (SUESS, 1979; SUESS et al., 1982). Figures 1 and 2 show data for dissolved total carbon dioxide, ammonia, and sulfate from several hemipelagic environments. From these values we have selected as typical the $\Sigma \mathrm{CO}_{2}: \mathrm{SO}_{4}^{-2}: \mathrm{NH}_{4}^{+}$molar ratios given by Eqns. (1) and (2):

$$
\begin{gathered}
{\left[\Sigma \mathrm{CO}_{2}\right]=2.33+0.0943\left[\mathrm{NH}_{4}^{+}\right]} \\
{\left[\Sigma \mathrm{CO}_{2}\right]=48.6-1.59\left[\mathrm{SO}_{4}^{-2}\right] .}
\end{gathered}
$$

We chose these equations to represent the regenerative ratios in organic-rich sediments, and not as a statistical fit to the data. In this investigation we evaluate the effect of metabolically induced changes in the $\Sigma \mathrm{CO}_{2}, \mathrm{SO}_{4}^{-2}$, and $\mathrm{NH}_{4}^{+}$ concentrations on the activity of the major seawater cations. To model the chemical equilibria in pore water, we use the computer program MINEQL (WESTALL et al., 1987) and concentrations for the $\Sigma \mathrm{CO}_{2}$ and $\mathrm{SO}_{4}^{-2}$ ligands characteristic of hemipelagic environments. We then extend the model to include the distribution of free, complexed, and adsorbed $\mathrm{Mg}^{+2}$, based on a mass balance for the dissolved and adsorbed $\mathrm{Mg}^{+2}$ components in the sediments. For this model we use empirical parameters for the magnesium adsorption equilibria and the previously determined constants for the $\mathrm{Mg}^{+2}$. $\mathrm{NH}_{4}^{+}$exchange (VON BREYMANN and SUESS, 1988), assuming for this first case a constant cation exchange capacity (CEC) through the sediment column. The empirical exchange parameters are based on adsorption isotherms for $\mathrm{Mg}^{+2}$ on sediments that describe these equilibria in a seawater matrix. With this model, we can quantify the effect of adsorption and ion exchange reactions on the distribution of dissolved $\mathrm{Mg}^{+2}$, particularly with respect to the observed dissolved ion 
maxima. By incorporating changes in the CEC of the sediments in the model, we can test the hypothesis that the shallow minimum in the dissolved $\mathrm{Mg}^{+2}$ distribution results from changes in the CEC of the sediments during the very early stages of anoxic diagenesis.

This type of analysis is essential to understand the geochemical behavior of $\mathrm{Mg}^{+2}$ in marine sediments, and it provides the necessary tools for including transport of $\mathrm{Mg}^{+2}$, resulting from ion exchange reactions, in its overall geochemical balance.

\section{MATERIALS AND METHODS}

\section{Dissolved Phase}

The ion-speciation model MINEQL (WESTALL et al., 1987) was used to calculate the chemical composition of pore waters at equilibrium. This program was developed to find the equilibrium composition of complex aqueous systems by minimizing the Gibbs free energy of the system subject to a set of mass balance constraints.

A large set of association constants for complex formation in seawater is available in the literature (PYTKOWICZ and KESTER, 1969; PytKowiCZ and HaWLeY, 1974; DRYSSEN and HANSSON, 1973; ATLAS et al., 1976; JOHANSON and WEDBORG, 1979); however, the composition of the pore fluids in highly reducing environments exhibits gross departures from that of seawater. To evaluate the effect of the solution chemistry on the association constants we have calculated activity coefficients for the main species present in the pore fluids and in seawater, using both extended DEBYE-HUCKEL and Pitzer (PITZer, 1973) equations. The results of this exercise show that the constants calculated by the various models differ more among themselves than those calculated using the same equation but varying the system from scawater to pore water compositions. Changes in the composition of the medium from seawater to highly altered pore water changes the values for the association constants by less than $1 \%$. This is probably because there is no major change in the ionic strength of the medium even when there are significant differences in the composition of the fluids.

MILLERO and SCHRIEBER (1982) have reviewed and compiled values for the conditional association constants determined by several workers. We have used these values to calculate the speciation of major ions in pore waters since they represent an internally consistent set of constants.

\section{Solid Phase}

We selected one sample from the Bransfield Strait basin, three samples from the Gulf of California, and one from the Peru margin to determine the empirical parameters that govern the $\mathrm{Mg}^{+2}$ adsorption equilibria in hemipelagic sediments. The location and description of the samples are listed in Table 1. The Bransfield Strait sample was recovered during $\mathrm{F} / \mathrm{S}$ Meteor Cruise \#65, the samples from DSDP Sites 475,478 , and 479 were kindly provided by Dr. Joris Gieskes and the sample from ODP Site 685 was obtained by E. Suess during drilling of Leg 112.

We have used a radiotracer technique described by vON BREYMANN et al. (1988) to measure the total exchangeable magnesium in these sediment samples as well as in a commercially available smectite clay (Wards Natural Science). The method is based on the measurement of adsorbed $\mathrm{Mg}^{+2}$ that resulted from the equilibration of the solid phase with a seawater medium spiked with ${ }^{27} \mathrm{Mg}^{+2}$. The samples were filtered through $45 \mu \mathrm{m}$ Millipore $@$ filters, and the ${ }^{27} \mathrm{Mg}^{+2}$ activity on the solid surface was counted using the $843.8 \mathrm{KeV}$ gamma ray in the well of a $3 \times 3^{\mathrm{N}} \mathrm{NaI}$-detector coupled to a multichannel analyzer. Using a similar technique, adsorption isotherms were obtained by equilibrating the samples in a series of ${ }^{27} \mathrm{Mg}^{+2}$ spiked seawater matrices, where the total dissolved magnesium concentration ranged from 10 to $60 \mathrm{mM}$. During all these experiments the temperature of the samples was maintained at $20 \pm 1^{\circ} \mathrm{C}$.

A similar technique was used to estimate conditional equilibrium exchange constants for the $\mathrm{Mg}^{+2}-\mathrm{NH}_{4}^{+}$exchange reactions at constant a magnesium concentration (vON BREYMANN et al., 1988). The total cation exchange capacity (CEC) in these samples was determined separately by exchange with ammonium chloride and measurement of the adsorbed ammonium in the solid phases.

\section{RESULTS}

\section{Interstitial Water Metabolites and Ligand Concentration}

Typical changes in metabolite concentrations represented by Eqns. (1) and (2) were used to obtain the speciation of major cations in the pore waters using the MINEQL program

TABLE 1. Location and description of the sediment samples used in the magnesium adsorption experiments.

\begin{tabular}{|c|c|c|c|c|}
\hline Sample & & Location & $\begin{array}{l}\text { Water depth } \\
\text { (m) }\end{array}$ & Description \\
\hline $\begin{array}{l}8101 \times 27 x \\
(9 \text { mbso })\end{array}$ & Bransficld Strait & $\begin{array}{l}62^{\circ} 16.5^{\prime} \mathrm{S} \\
57^{\circ} 38.8^{\mathrm{r}} \mathrm{W}\end{array}$ & 1950 & $\begin{array}{l}\text { Glacial marine deposits, chanacterized } \\
\text { by terrestrial and yolcanogenic turbidites } \\
\text { Calcium hexahydrates at } 7 \mathrm{~m} .1\end{array}$ \\
\hline $\begin{array}{l}\text { DSDP } 475 \\
(153 \mathrm{mbxf})\end{array}$ & Gulf of California & $\begin{array}{l}20^{\circ} 03.033^{\prime} \mathrm{N} \\
109^{\circ} 03.19^{\prime} \mathrm{W}\end{array}$ & 2631 & $\begin{array}{l}\text { Diatomaceous hemipelagic with mud } \\
\text { tubidites. Dolostone at } 150 \mathrm{~m} \\
\text { depth. Meuvolaric, metasedinentray } \\
\text { rocks below } 160 \mathrm{~m} .2\end{array}$ \\
\hline $\begin{array}{l}\text { DSDP } 478 \\
(158 \mathrm{mbsf})\end{array}$ & Gulf of Califomia & $\begin{array}{l}27^{\circ} 05.81^{\prime} \mathrm{N} \\
111^{\circ} 30.45^{\prime} \mathrm{W}\end{array}$ & 1889 & $\begin{array}{l}\text { Diatomaceous muds and silty turdidites. } \\
\text { Dolomitic siltstones and doleritic silt } \\
\text { intrusions between } 188 \text { and } 260.2\end{array}$ \\
\hline $\begin{array}{l}\text { DSDP } 479 \\
(34 \mathrm{mb} \times \mathbf{f})\end{array}$ & Gulf of Califomia & $\begin{array}{l}27^{\circ} 50.76^{\circ} \mathrm{N} \\
111^{\circ} 37.49^{\prime} \mathrm{W}\end{array}$ & 747 & $\begin{array}{l}\text { Unifom hemipelagic sequence of } \\
\text { hemipelagic muddy diatomacoeus ooze } \\
\text { to mudstone, with intercalated thin hard } \\
\text { dolomite layers. }\end{array}$ \\
\hline $\begin{array}{l}\text { ODP 685 } \\
\text { (265 mbef) }\end{array}$ & Penu Margin & $\begin{array}{l}9 \circ 06.78^{*} \mathrm{~S} \\
80^{\circ} 35.01^{\prime} \mathrm{W}\end{array}$ & 5070 & $\begin{array}{l}\text { Diatomaceous muds to diatom bearing } \\
\text { mudstones, with small concentrations } \\
\text { of authigenic calcite and dolomite. } 3\end{array}$ \\
\hline
\end{tabular}

1 Han, 1987; Hollex, 1985.

2 Curray and Moore, 1982

2 Suess et al., 1987. 


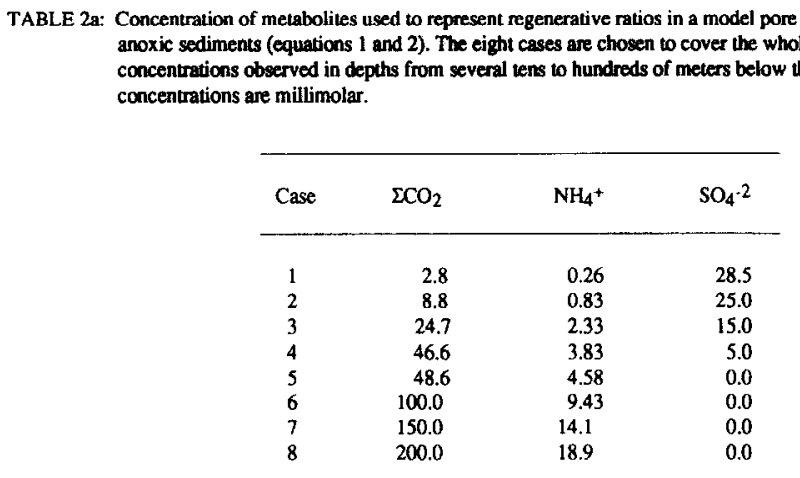

with the association constants reported by MILLERO and SCHREIBER (1982). The results listed in Table 2 show no significant changes in ion pairing for $\mathrm{Na}^{+}$or $\mathrm{K}^{+}$(Fig. 3), which is not surprising since these cations exist mainly as free species in seawater. $\mathrm{Mg}^{+2}$ and $\mathrm{Ca}^{+2}$, on the other hand, form strong complexes with both $\mathrm{CO}_{3}^{-2}$ and $\mathrm{SO}_{4}^{-2}$ ions. During the initial stages of decomposition of organic matter by sulfate reduction, the removal of sulfate coupled with the release of carbonate has opposite effects on the free ion concentrations, so that changes in the activity of $\mathrm{Mg}^{+2}$ and $\mathrm{Ca}^{+2}$ are insignificant in the sulfate-reducing zone (Fig. 4). After sulfate depletion, however, complexation by $\mathrm{CO}_{3}^{-2}$ becomes important in reducing the concentration of the free ion. For example, a concentration of $60 \mathrm{mM} \Sigma \mathrm{CO}_{2}$ decreases the free ion concentrations of $\mathrm{Ca}^{+2}$ and $\mathrm{Mg}^{+2}$ by approximately $15 \%$.

To illustrate the free $\mathrm{Mg}^{+2}$ distribution in natural environments, we have used the pore water data reported by GIESKES et al. (1982) and BRUMSACK and GIESKES (1983) for the Gulf of California, SUEss et al. (1982) for the Bransfield Strait, and SUEșS et al. (1988) for the Peru margin. The results are shown in Fig. 5, in which the ammonium, sulfate, and dissolved magnesium profiles were constructed from published data. The $\Sigma \mathrm{CO}_{2}$ ion distributions were calculated using the $\mathrm{pH}$ and alkalinity data for these cores, together with the apparent dissociation constants for carbonic acid reported by MiLLERO and SCHREIBER (1982). The deviation of pore water $\mathrm{Mg}^{+2}$ from the seawater value $\left[\Delta \mathrm{Mg}^{+2}\right]_{\mathrm{Pw}}$ was obtained by subtracting the $\mathrm{Mg}^{+2}$ contribution of seawater at normal salinity from the measured total dissolved magnesium in the pore waters. The total dissolved magnesium includes both the free $\mathrm{Mg}^{+2}$ ion and the magnesium complexed by pore water ligands. The free $\mathbf{M g}^{+2}$ shown in Fig. 5 as a percentage of the total dissolved $\mathrm{Mg}^{+2}$ was obtained using the program MINEQL.

It is of particular relevance to the understanding of the geochemical behavior of magnesium that the minima in the percent free $\mathrm{Mg}^{+2}$ at depth always coincide with the $\mathrm{\Sigma CO}_{2}$ maxima below the sulfate-reducing zone. These minima seem also coincident with a maximum in the total dissolved $\mathrm{Mg}^{+2}$, as emphasized by the " $\mathrm{Mg}^{+2}$-deviation" plots. We postulate

\begin{tabular}{|c|c|c|c|c|c|c|c|c|}
\hline Case & $\mathrm{Mg}^{+2}$ free ion & $\mathrm{Mg} \cdot \mathrm{SO}_{4}$ & $\mathrm{Mg} \cdot \mathrm{CO}_{3}$ & $\mathrm{Mg}^{+2}$ free $(\%)$ & $\mathrm{Ca}^{+2}$ free ion & $\mathrm{Ca} \cdot \mathrm{SO}_{4}$ & $\mathrm{Ca} \cdot \mathrm{CO}_{3}$ & $\mathrm{Ca}^{+2}$ free $(\%)$ \\
\hline 1 & 48.8 & 5.3 & 0 & 85.0 & 9.2 & 1.1 & 0 & 89.3 \\
\hline 2 & 48.4 & 4.9 & 0.9 & 84.3 & 9.0 & 0.9 & 0.4 & 87.4 \\
\hline 3 & 47.9 & 2.9 & 3.9 & 83.4 & 8.8 & 0.9 & 0.6 & 85.4 \\
\hline 4 & 47.2 & 0.9 & 6.4 & 82.2 & 8.6 & 0.2 & 1.5 & 83.5 \\
\hline 5 & 47.0 & 0.0 & 7.6 & 81.9 & 8.5 & 0.0 & 1.8 & 82.5 \\
\hline 6 & 40.5 & 0.0 & 14.0 & 70.5 & 7.1 & 0.0 & 3.2 & 68.9 \\
\hline 7 & 35.7 & 0.0 & 19.0 & 62.2 & 6.0 & 0.0 & 4.3 & 58.2 \\
\hline 8 & 31.7 & 0.0 & 26.7 & 55.2 & 5.3 & 0.0 & 5.0 & 51.4 \\
\hline Case & $\mathrm{Na}^{+}$free ion & $\mathrm{Na} \cdot \mathrm{SO}_{4}$ & $\mathrm{Na} \cdot \mathrm{CO}_{3}$ & $\mathrm{Na}^{+}$free $(\%)$ & $\mathrm{K}^{+}$free ion & $\mathrm{K} \cdot \mathrm{SO}_{4}$ & & $\mathrm{~K}^{+}$free $(\%)$ \\
\hline 1 & 473 & 9.2 & 0 & 97.9 & 11.0 & 0.2 & & 98.3 \\
\hline 2 & 473 & 9.2 & 0 & 97.9 & 11.0 & 0.2 & & 98.3 \\
\hline 3 & 475 & 5.8 & 0 & 98.2 & 11.0 & 0.2 & & 98.3 \\
\hline 4 & 478 & 2.9 & 2.9 & 98.8 & 11.2 & 0 & & 100 \\
\hline 5 & 477 & 0 & 6.8 & 98.6 & 11.2 & 0 & & 100 \\
\hline 6 & 471 & 0 & 9.2 & 97.4 & 11.2 & 0 & & 100 \\
\hline 7 & 465 & 0 & 14.0 & 96.1 & 11.2 & 0 & & 100 \\
\hline 8 & 458 & 0 & 25.1 & 94.8 & 11.2 & 0 & & 100 \\
\hline
\end{tabular}




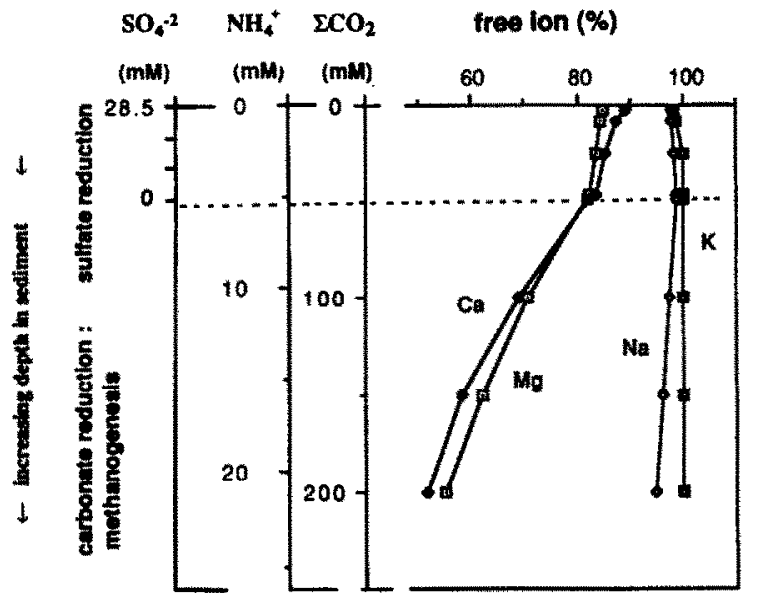

Fio. 3. Variation of the percentage of major cations present as free ions resulting from changes in the pore water composition due to organic matter diagenesis. Carbonate and ammonia concentrations increase with progressive diagenesis, coupled with a depletion and eventual exhaustion sulfate ions. The depth ranges corresponding to these dissolved cations vary significantly among hemipelagic environments (Fig. 5), depending on the corresponding sedimentation rates and the organic carbon content of the sediments. that the decrease in the free $\mathrm{Mg}^{+2}$ plays an important role in re-adjusting the $\mathrm{Mg}^{+2}$ adsorption equilibria and also affects the exchange of the competing ammonium ion. Combined, these two effects may well be responsible for the maxima in total magnesium, as will be discussed in the subsequent sections.

\section{Magnesium Adsorption in Marine Sediments}

Cations adsorbed to solid surfaces are in equilibrium with their respective dissolved free ion concentrations, so that changes in the dissolved matrix will result in predictable changes of the adsorbed ion fractions. These equilibrium processes can be parameterized by adsorption isotherms (STUMM and MORGAN, 1981; BERNER, 1980). In this section we report results obtained for an estimate of the total exchangeable magnesium on various bulk sediments and the characteristic parameters of magnesium adsorption isotherms in equilibrium with a seawater matrix. This will allow us to quantify the response of the solid-solution system to changes in the free magnesium ion concentration.

The total exchangeable magnesium (TEM) on the samples $\mathbf{a}$

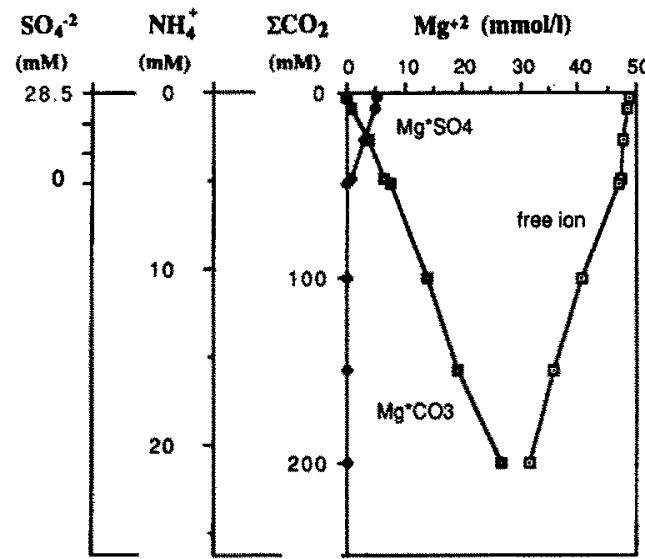

b

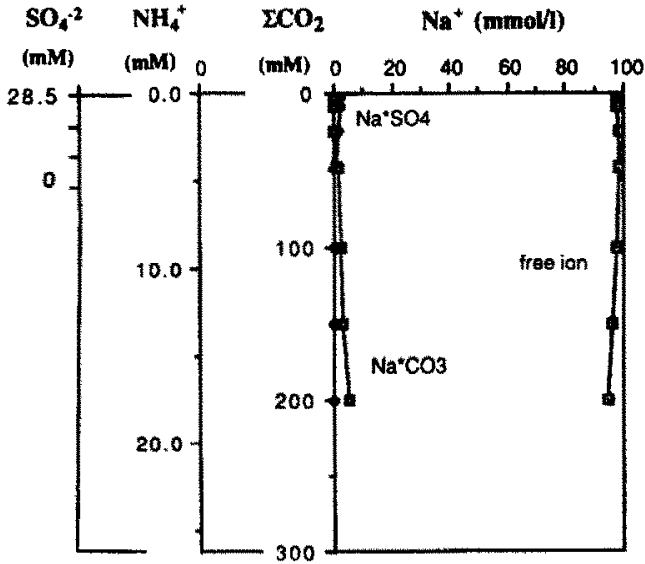

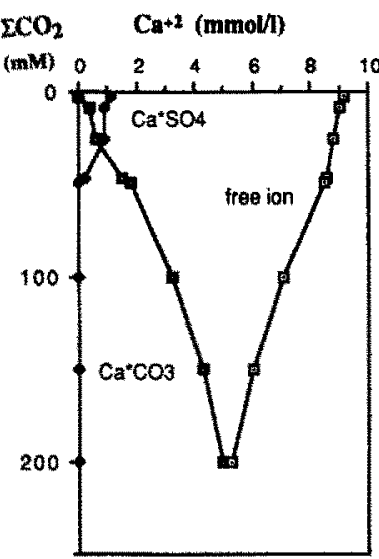

$\mathrm{xCO}_{2} \quad \mathbf{K}+(\mathrm{mmol} / \mathrm{m})$

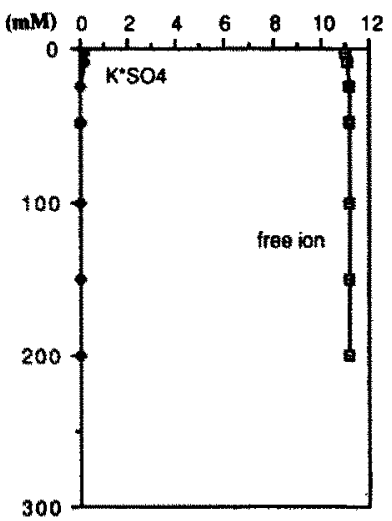

FIG 4. (a) Changes in the speciation of $\mathrm{Mg}^{+2}$ and $\mathrm{Ca}^{+2}$ in pore fluids that resulted from diagenetic changes in the metabolite concentrations. (b) Changes in the speciation of $\mathrm{Na}^{+}$and $\mathrm{K}^{+}$in pore fluids that resulted from diagenetic changes in the metabolite concentrations. 
a
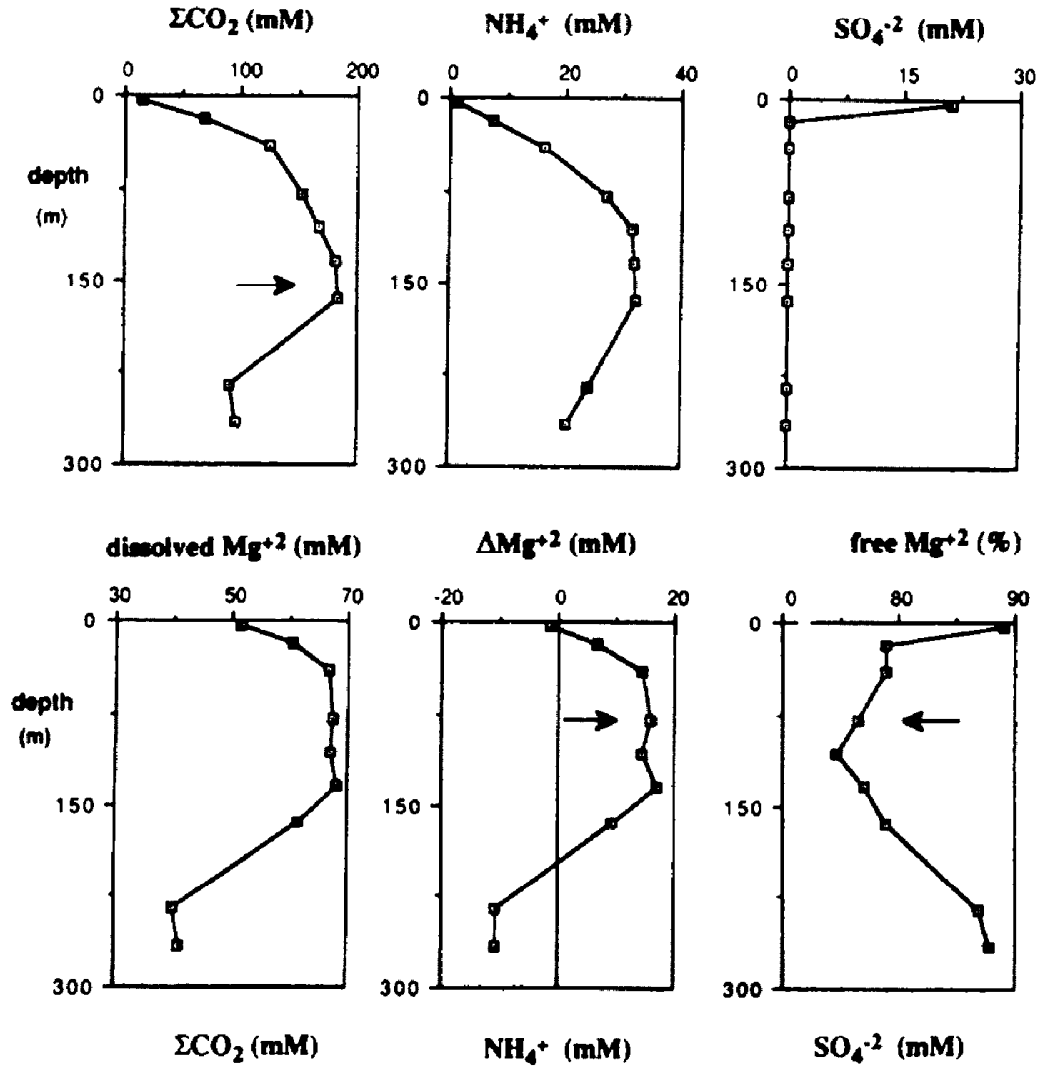

b
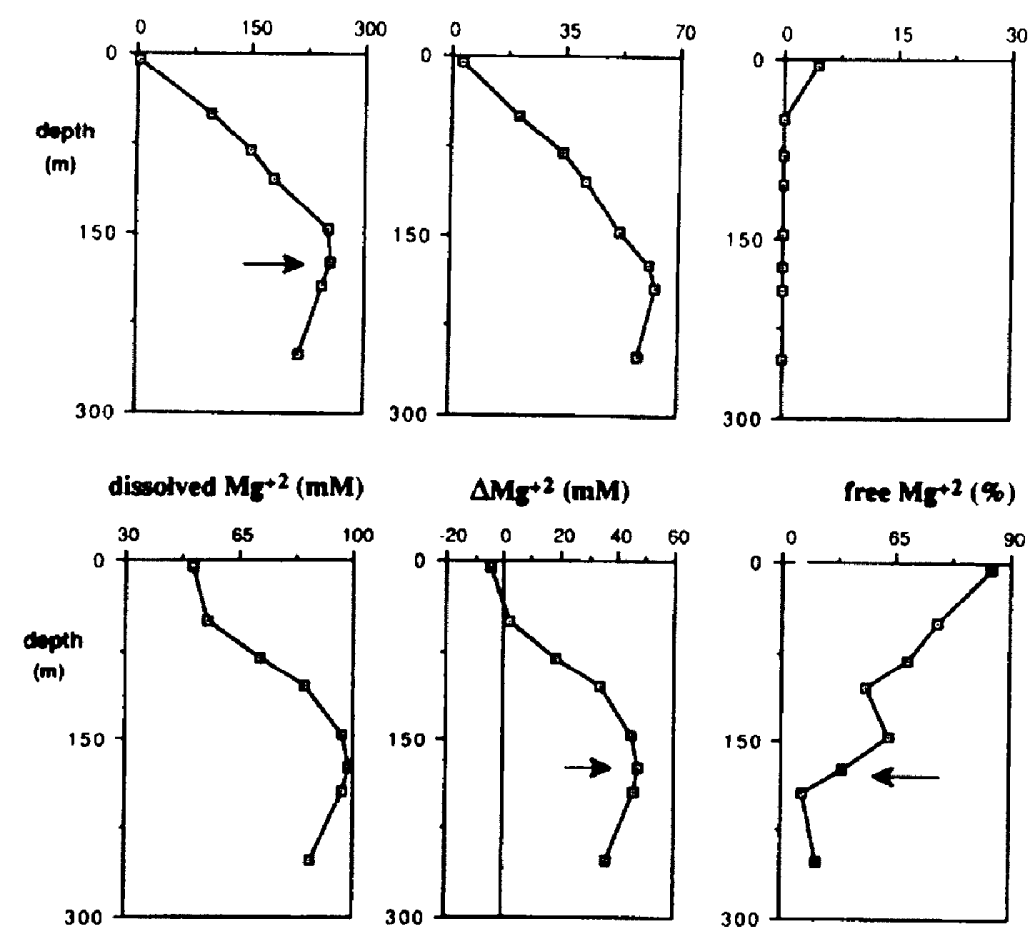

FiG. 5. (a) Downcore distributions of total dissolved $\mathrm{CO}_{2}, \mathrm{NH}_{4}^{+}, \mathrm{SO}_{4}^{-2}$, and $\mathrm{Mg}^{+2} ; \mathrm{Mg}^{+2}$ deviations from the seawater value $\left[\Delta \mathrm{Mg}^{+2}\right]_{p w}$; and free $\mathrm{Mg}^{+2}$ ion concentrations in the Peru margin, ODP Site 685 . The dissolved $\mathrm{Mg}^{+2}$ maxima coincides with very high $\Sigma \mathrm{CO}_{2}$ values and with the corresponding decrease in free $\mathrm{Mg}^{+2}$ ions, as indicated by the arrows. Data for total dissolved constituents from Suess et al. (1988); free ion concentrations were calculated with MINEQL. (b) Same as (a) for ODP Site 688 (Peru margin). (c) Same as above for DSDP Site 478 (Gulf of California). Data for total dissolved constituents from Gieskes et al. (1982); free ion concentrations were calculated with MINEQL. (d) For DSDP Site 479 (Gulf of California). Data for total dissolved constituents from Gieskes et al. (1982); free ion concentrations were calculated with MINEQL. (e) For Bransfield Strait, Core \#8101-278. Data for total dissolved constituents from HAN (1987); free ion concentrations were calculated with MINEQL. 
c $\mathrm{\Sigma CO}_{2}(\mathbf{m M})$

$\mathrm{NH}_{\mathbf{4}}+(\mathbf{m M})$ $\mathrm{SO}_{4}^{-2}(\mathrm{mM})$
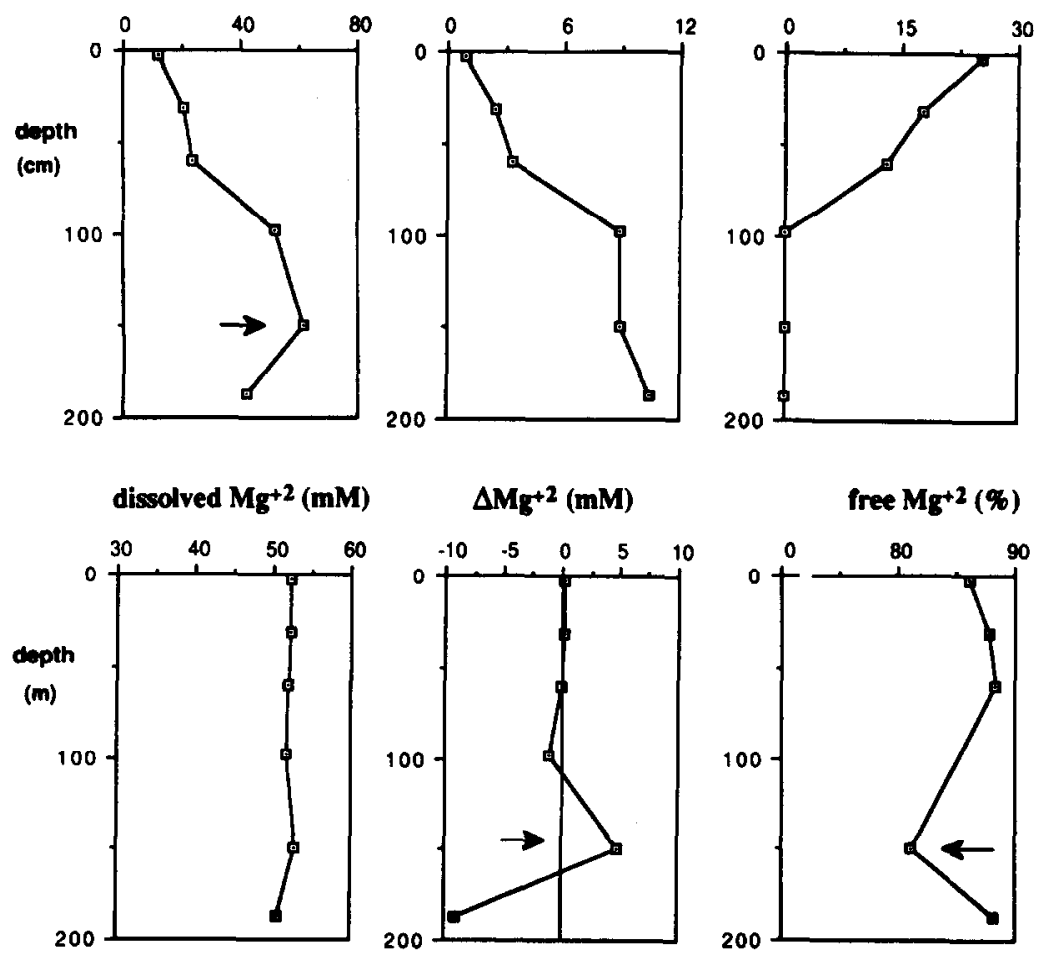

d $\mathrm{SO}_{4}^{-2}(\mathrm{mM})$ $\mathrm{NH}_{4}+(\mathrm{mM})$
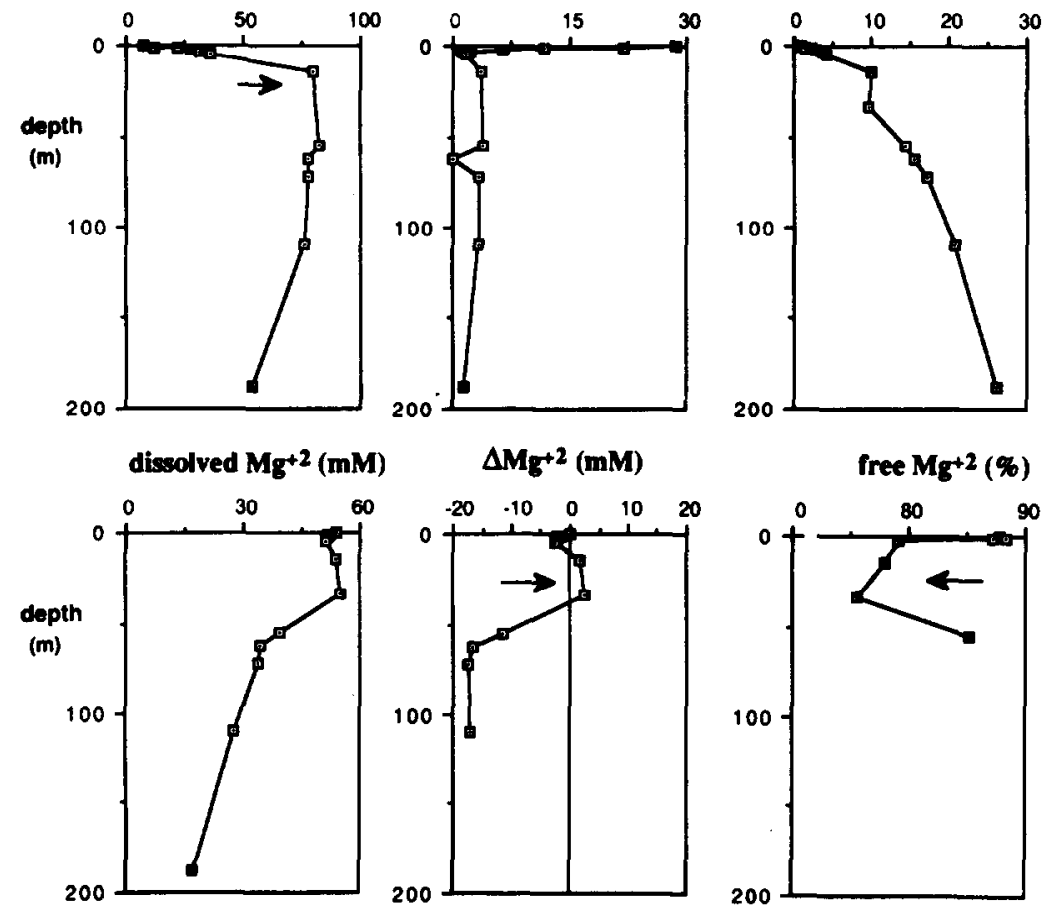

FIG. 5. (Continued)

equilibrated in a seawater medium and their total cation exchange capacity (CEC) are listed in Table 3. In all cases, when the sample has been equilibrated in a seawater matrix, the magnesium occupies approximately $40 \%$ of the total available exchange sites. This result was previously reported for the $\mathrm{Mg}^{+2}$ adsorption on clays and undissolved humic acid (VON BREYMANN and SUESS, 1988), and implies that samples with higher $\mathrm{CEC}$ will have a higher concentration 
e
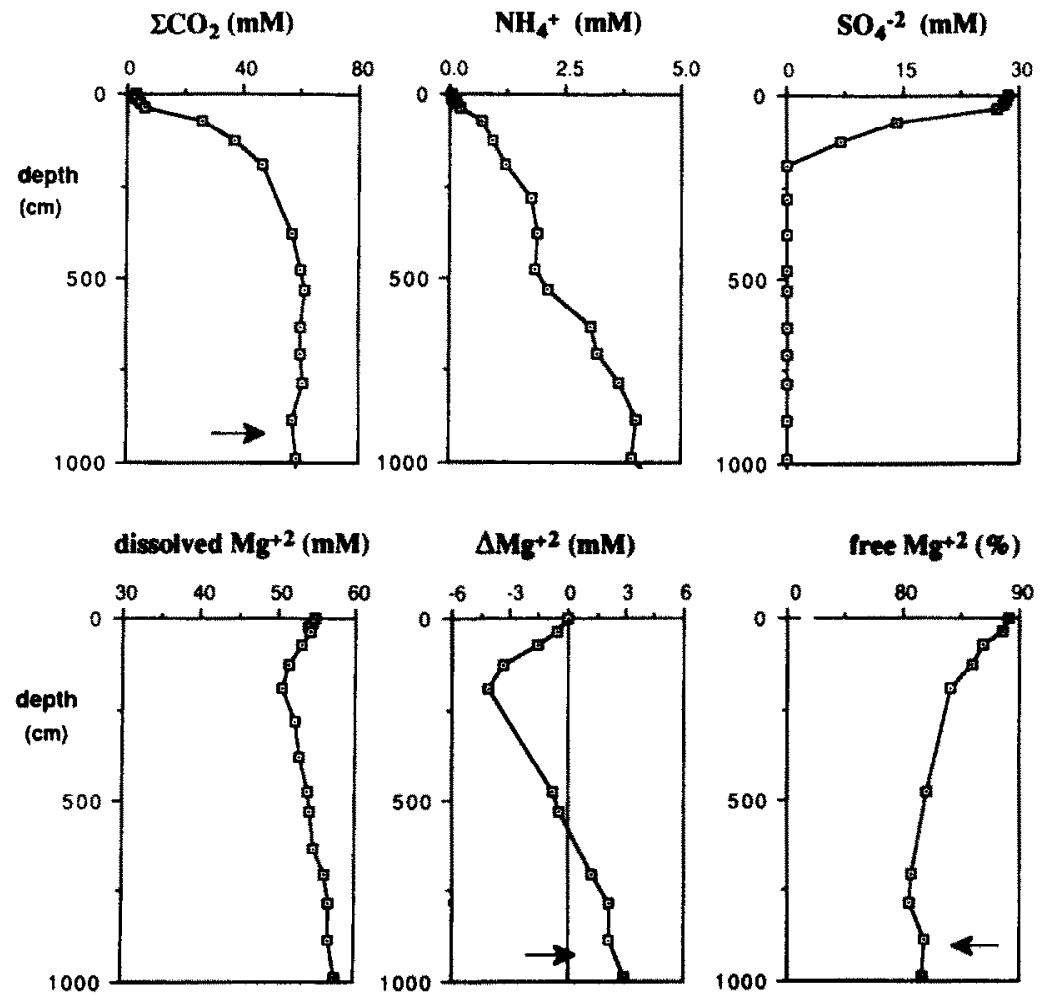

Fio. 5. (Continued)

of surface adsorbed $\mathrm{Mg}^{+2}$ and, furthermore, that this TEM level can be approximated by simply estimating $40 \%$ of the CEC of any sample.

The relationship between the dissolved free $\mathrm{Mg}^{+2}$ concentration and the amount of adsorbed $\mathrm{Mg}^{+2}$ expressed as the fraction of the total cation exchange capacity $\left(X_{\mathrm{Mg}}\right)$ at constant temperature is plotted in a series of adsorption isotherms shown in Fig. 6. This approach is analogous to the theoretical Langmuir model that relates the activity of the dissolved species to the fraction of the total surface covered by this species (STUMM and MORGAN, 1981; BERNER, 1980), so that

$$
X_{\mathrm{Mg}}=\frac{\alpha \cdot\left[\mathrm{Mg}^{+2}\right]_{\mathrm{F}}}{\beta+\left[\mathrm{Mg}^{+2}\right]_{F}}
$$

where $\left[\mathrm{Mg}^{+2}\right]_{\mathrm{F}}$ represents the concentration of free dissolved magnesium in mol/L at equilibrium, and $\alpha$ and $\beta$ are empirical constants for a given temperature. $X_{\mathrm{Mg}}$ represents the amount of adsorbed magnesium expressed as a fraction of the total cation exchange capacity. Plots of $1 / X_{\mathrm{M}_{8}}$ versus $1 /$ $\left[\mathrm{Mg}^{+2}\right]_{\mathrm{F}}$, shown in Fig. 7 , were used to obtain the empirical constants $\alpha$ and $\beta$. Values for these constants for each of the samples analyzed are listed in Table 3.

\section{Magnesium-Ammonium Exchange}

The $\mathrm{Mg}^{+2}$ adsorption equilibria depend not only on the free $\mathrm{Mg}^{+2}$ but also on the concentration of other dissolved cations that compete for the sites on the solid surface. It is

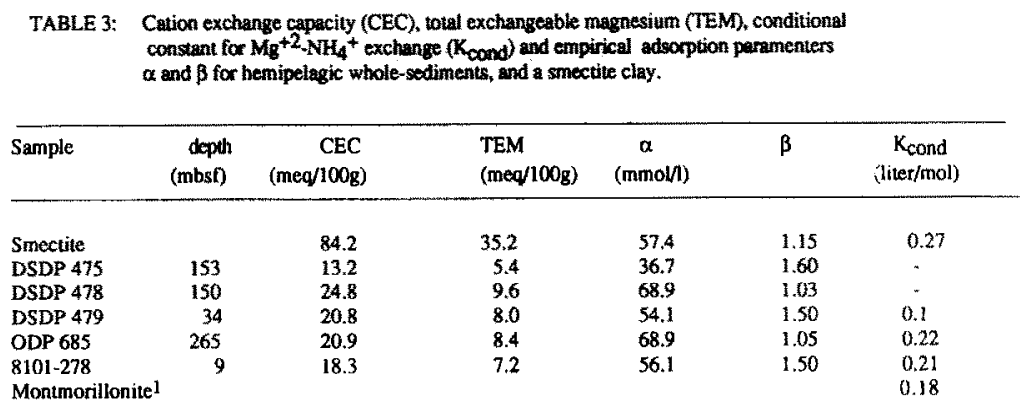

${ }^{1} K_{\text {cond from Laudelout et al. (1967) }}$ 

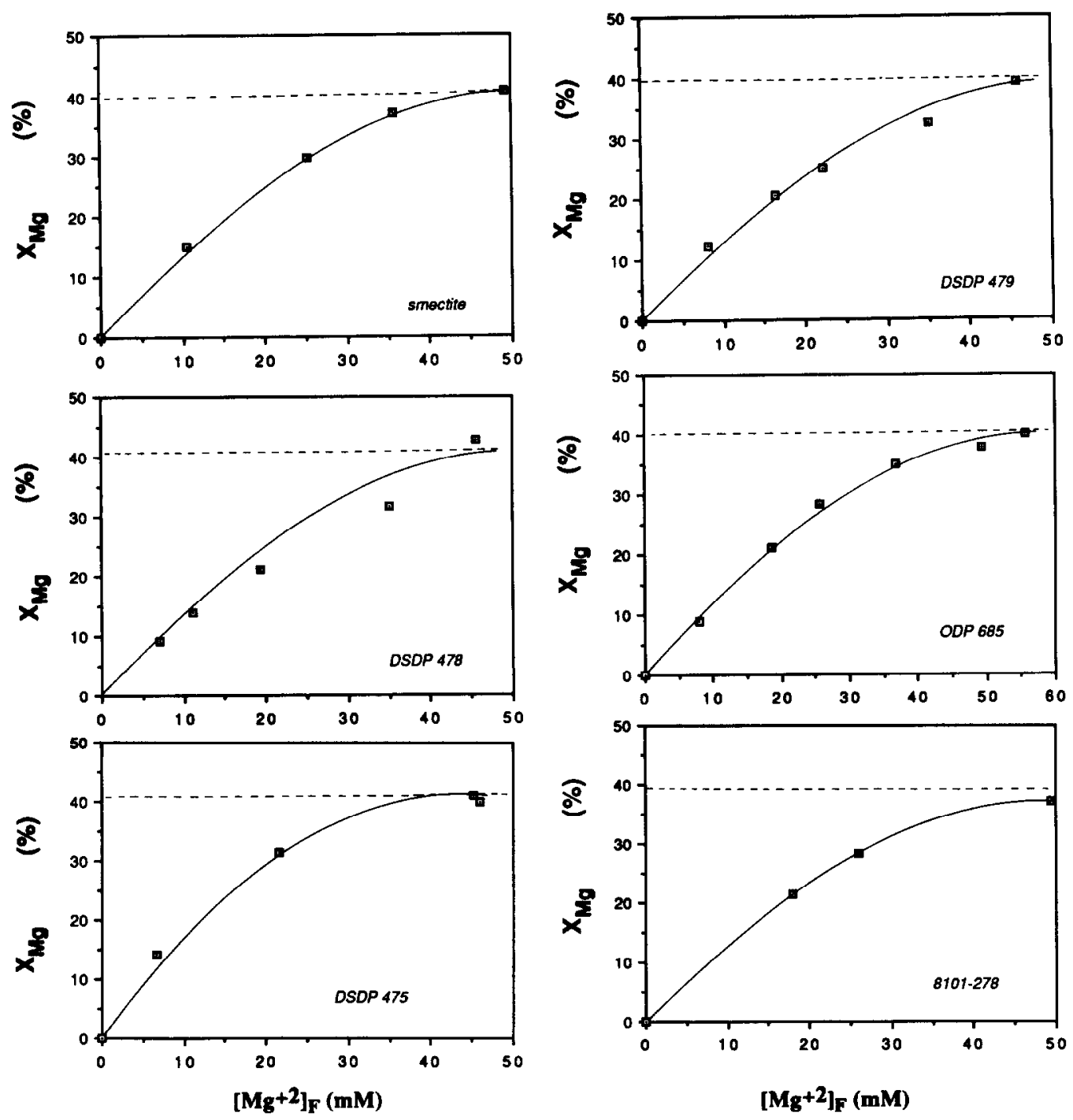

FIG. 6. Magnesium adsorption isotherms for a smectite clay and five hemipelagic sediment samples.

well established that large quantities of ammonium are released by the decomposition of sedimentary organic matter which in turn could mobilize $\mathrm{Mg}^{+2}$ from solid phases by ion exchange (BOATMAN and MURRAY, 1982; GIESKES et al., 1982; ROSENFELD, 1979). A conditional equilibrium exchange constant for this equilibrium can be defined by

$$
K_{\text {cond }}=\frac{\left[\mathrm{Mg}^{+2}\right]_{\mathrm{F}}}{X_{\mathrm{Mg}}} \cdot \frac{X_{\mathrm{NH} 4}^{2}}{\left[\mathrm{NH}_{4}^{+}\right]_{\mathrm{F}}^{2}} .
$$

As we have shown in the previous sections, the pore fluids in hemipelagic sediments show major deviations from the seawater composition, which significantly affects the free $\mathrm{Mg}^{+2}$ concentrations. Changes in the concentration of free $\mathrm{Mg}^{+2}$ will affect this equilibrium; for this reason, we have defined $K_{\text {cond }}$ in terms of their free ion contents, so as to make it applicable to systems with pore waters of varying composition. Table 3 lists the $\boldsymbol{K}_{\text {cond }}$ values used in this study which compare well with the value for the $\mathrm{Mg}^{+2}-\mathrm{NH}_{4}^{+}$exchange constant estimated by LAUDELOT et al. (1967) for a montmorillonite clay.

Part of the magnesium released by ammonium exchange is also subject to re-adsorption on the surfaces following the isotherms described previously. The extent of the solid surface and complexation reactions in the pore fluid-solid sediment system can only be fully quantified by a multi-component reaction model, as shown in the next section.

\section{DISCUSSION}

\section{A Multi-component Model}

The interdependent processes to be modeled are schematically represented in Fig. 8 . The objective of this model 

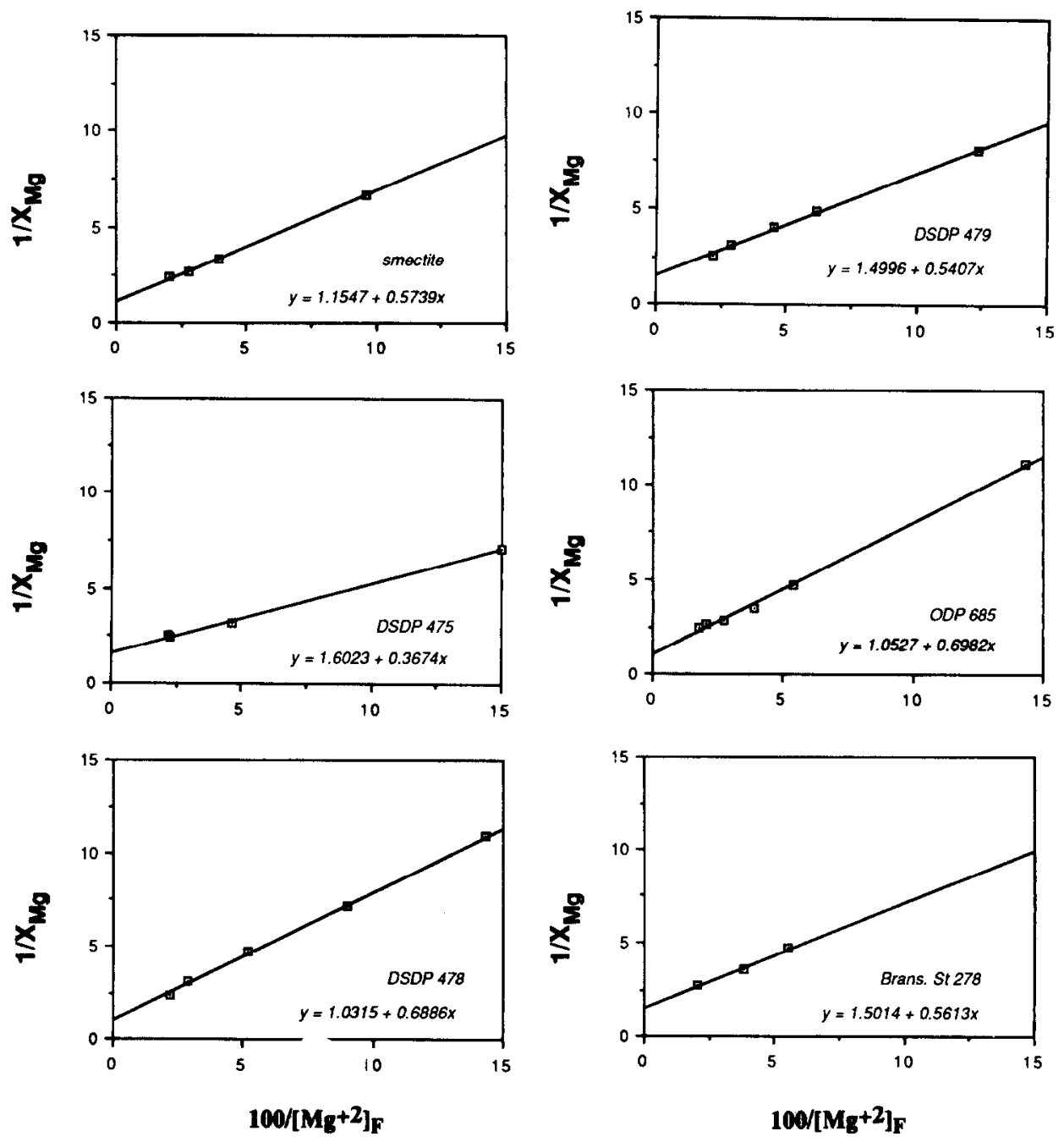

FIG. 7. Langmuir-type plots for the magnesium adsorption.

is to allow a quantitative determination of the equilibrium conditions for the solid-pore water system as a function of the pore water composition. We have used a mass balance approach for the mathematical description of the problem and an iterative computer program for the computation of the equilibrium composition of the system. Due to the nature of the experimental conditions used to determine the empirical parameters that govern the various equilibria, we can treat both magnesium adsorption and ion exchange as independent "boxes" even when in natural systems both processes occur simultaneously.

We have stated the multi-component model as a mass balance for a closed system in terms of "reactive" magnesium. That is, it is limited only to the dissolved $\left\langle\mathrm{Mg}^{+2}\right\rangle_{\mathrm{D}}$ and adsorbed $\left\langle\mathrm{Mg}(\mathrm{Sfc})_{2}\right\rangle$ species and does not include any magnesium fixed in crystal lattices. Thus, the total reactive magnesium $\left\langle\mathbf{M g}^{+2}\right\rangle_{\text {Tот }}$ will be

$$
\left\langle\mathrm{Mg}^{+2}\right\rangle_{\mathrm{TOT}}=\left\langle\mathrm{Mg}(\mathrm{Sfc})_{2}\right\rangle+\left\langle\mathrm{Mg}^{+2}\right\rangle_{\mathbf{D}}
$$

where all concentrations are given in millimoles per liter of wet sediment. The dissolved component can be expressed in millimoles per liter of pore water, $\left[\mathrm{Mg}^{+2}\right]_{\mathrm{D}}$, the more commonly used units for dissolved components if the porosity $(\Phi)$ of the sediments is known.

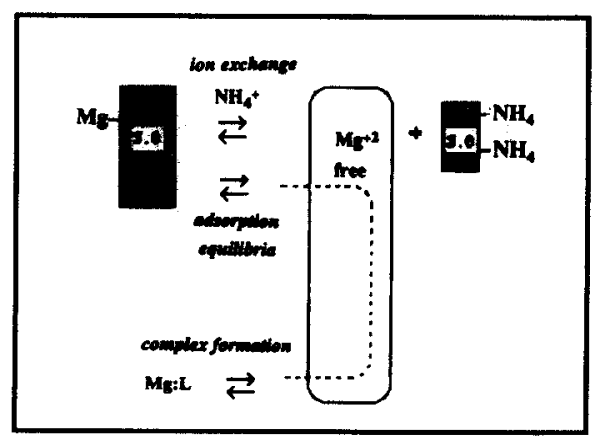

FIG. 8. Simultaneous reactions representing the Mg-adsorption, ion exchange, and complex formation in the solid-pore water system. The competition for $\mathrm{Mg}^{+2}$ between the pore water ligands $\left(\mathrm{CO}_{3}^{-2}, \mathrm{SO}_{4}^{-2}\right)$ and the surface sites in the solid exchanger (s.e.) is indicated by the dotted line. 
The amount of magnesium adsorbed to the solids at any depth, will be a function of both the free $\mathrm{Mg}^{+2}$ and any other competing cations; in our case, we want to evaluate the magnesium released by ammonium exchange. By the nature of our empirical parameters the equilibrium value for adsorbed magnesium can be estimated by

$$
\begin{aligned}
\left\langle\mathrm{Mg}(\mathrm{Sfc})_{2}\right\rangle_{z}=\left(\left\{\mathrm{Mg}(\mathrm{Sfc})_{2}\right\}_{\mathrm{NH} 4-0}\right. & \\
& \left.-\left\{\mathrm{NH}_{4}(\mathrm{Sfc})\right\}_{\mathrm{Mg}}\right) \cdot \rho_{z} \cdot 5
\end{aligned}
$$

where $\rho_{z}$ represents the dry bulk density in units of grams per milliliter of sediment, and the dimensionless constant 5 results from the conversion from millimoles to liters and equivalents to moles of magnesium. $\left\{\mathrm{Mg}(\mathrm{Sfc})_{2}\right\}_{\mathrm{NH} 4=0}$ represents the amount of adsorbed magnesium in equilibrium with a given free $\mathrm{Mg}^{+2}$, at zero ammonium. It can be estimated from Eqn. (3) and rewritten as

$$
\left\{\mathrm{Mg}(\mathrm{SfC})_{2}\right\}_{\mathrm{NH}_{4}=0}=\frac{\mathrm{CEC}\left[\mathrm{Mg}^{+2}\right]_{\mathrm{F}}}{\left(\alpha+\beta\left[\mathrm{Mg}^{+2}\right]_{\mathrm{F}}\right)} \text {. }
$$

The amount of $\mathrm{Mg}^{+2}$ released from the surface as a result of ammonium exchange, $\left\{\mathrm{NH}_{4}(\mathrm{Sfc})\right\}_{\mathrm{Mz}}$, can be estimated from Eqn. (4) and rewritten as

$$
\begin{aligned}
\left\{\mathrm{NH}_{4}(\mathrm{Sfc})\right\}_{\mathrm{Mg}} & \\
= & {\left[\mathrm{NH}_{4}^{+}\right] \cdot K_{\text {cond }} \cdot \mathrm{CEC} \cdot \frac{\left\{\mathrm{Mg}(\mathrm{Sfc})_{2}\right\}^{1 / 2}}{\left[\mathrm{Mg}^{+2}\right]_{\mathrm{F}}} . }
\end{aligned}
$$

\section{Case 1: System free of ammonium}

At any given depth $z$, we will have in the pore water an amount of dissolved magnesium given by

$$
\left[\mathrm{Mg}^{+2}\right]_{\mathrm{D}, \mathrm{z}}=\left(\left\langle\mathrm{Mg}^{+2}\right\rangle_{\mathrm{TOT}}-\left\langle\mathrm{Mg}(\mathrm{Sfc})_{2}\right\rangle_{\mathrm{I}}\right) \cdot \phi^{-1}
$$

or

$$
\left[\mathrm{Mg}^{+2}\right]_{\mathrm{D}, z}=\frac{\left\langle\mathrm{Mg}^{+2}\right\rangle_{\mathrm{TOT}}}{\phi_{z}}-\frac{\mathrm{CEC} \cdot\left[\mathrm{Mg}^{+2}\right]_{\mathrm{F}}}{\alpha+\beta\left[\mathrm{Mg}^{+2}\right]_{\mathrm{F}}} \cdot \frac{\rho_{z}}{\phi_{z}} \cdot 5 .
$$

From Eqn. (10) we can see that a change in free magnesium ions will result in a redistribution of this cation between the solid and dissolved phases, affecting the total dissolved $\mathrm{Mg}^{+2}$ concentration. This equation, however, does not provide the final value for the dissolved $\mathrm{Mg}^{+2}$, but an instantaneous one, since this new $\left[\mathrm{Mg}^{+2}\right]_{\mathrm{D}, 2}$ will in turn change the value of free $\mathrm{Mg}^{+2}$, which then will vary the dissolved/adsorbed ratio, and so on. Therefore, we can arrive at the equilibrium conditions by a series of iterations defining

$$
\delta \mathrm{Mg}^{+2}=\left[\mathrm{Mg}^{+2}\right]_{\mathrm{D}, n-1}-\left[\mathrm{Mg}^{+2}\right]_{\mathrm{D}, n}
$$

where $n \geq 1$ is the iteration number, and $n=0$ represents the starting conditions. Then, $\delta \mathrm{Mg}^{+2}$ can be obtained from

$$
\begin{aligned}
\delta \mathrm{Mg}^{+2}=\left(\left\{\mathrm{Mg}(\mathrm{Sfc})_{2}\right\}_{n-1}\right. & \\
& \left.-\left\{\mathrm{Mg}(\mathrm{Sfc})_{2}\right\}_{n}\right) \cdot\left(10 \rho_{z} / 2 \phi_{z}\right)
\end{aligned}
$$

and the iterative process can be continued until the equilibrium conditions are attained, i.e., when $\delta \mathrm{Mg}^{+2} \approx 0$.

\section{Case 2: System with ammonium present}

In this case the total dissolved magnesium can be calculated from Eqns. (6) and (9) as

$$
\begin{aligned}
{\left[\mathrm{Mg}^{+2}\right]_{\mathrm{D}, z}=\left(\left\langle\mathrm{Mg}^{+2}\right\rangle_{\mathrm{TOT}}\right.} & -\left(\left\{\mathrm{Mg}(\mathrm{Sfc})_{2}\right\}_{\mathrm{NH} 4=0}\right. \\
& \left.\left.-\left\{\mathrm{NH}_{4}(\mathrm{Sfc})_{\mathrm{Mg}_{\mathrm{g}}}\right\}\right) 5 \rho \phi^{-1}\right)
\end{aligned}
$$

and the equilibrium conditions may be obtained iteratively by minimizing $\delta \mathrm{Mg}^{+2}$. For the system with ammonium present

$$
\begin{aligned}
\delta \mathrm{Mg}^{+2}= & \left(\left(\left\{\mathrm{Mg}(\mathrm{Sfc})_{2}\right\}-\left\{\mathrm{NH}_{4}(\mathrm{Sfc})\right\}\right)_{n-1}\right. \\
& \left.-\left(\left\{\mathrm{Mg}(\mathrm{Sfc})_{2}\right\}-\left\{\mathrm{NH}_{4}(\mathrm{Sfc})\right\}\right)_{n}\right) 5 \rho_{z} \phi_{z}^{-1} .
\end{aligned}
$$

The program used for the iterative calculations of the equilibrium conditions is a simple routine that solves the surface reactions stated above, subject to the free ion concentrations calculated by MINEQL. A flow diagram for the program is given in Fig. 9.

\section{Effect of Early Diagenesis on Magnesium Adsorption and Ion Exchange in Marine Sediments}

The decomposition of organic matter in hemipelagic sediments results in the depletion of $\mathrm{SO}_{4}^{-2}$, and in the accumulation of high levels of $\mathrm{NH}_{4}^{+}$and $\mathrm{CO}_{3}^{-2}$ in the pore fluids. As shown previously these compositional changes have significant effects on the speciation of $\mathrm{Mg}^{+2}$, and consequently

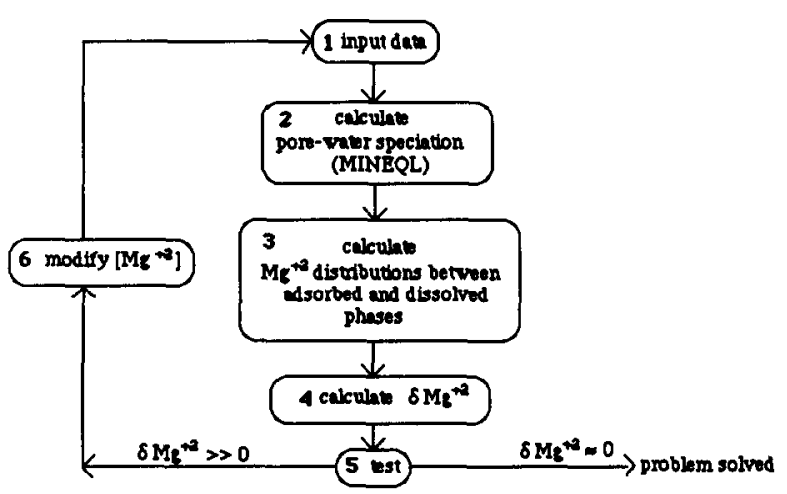

FIG. 9. Iterative computation of the equilibrium conditions for the multi-component model involving $\mathrm{Mg}$ speciation, adsorption, and ion exchange reactions. The data set entered in step 1 corresponds to the measured concentrations of all relevant constituents $\left(\mathrm{Na}^{+}\right.$, $\mathrm{K}^{+}, \mathrm{Ca}^{+2}, \mathrm{CO}_{3}^{-2}, \mathrm{SO}_{4}^{-2}, \mathrm{NH}_{4}^{+}, \mathrm{PO}_{4}^{-3}, \mathrm{Cl}^{-}, \mathrm{F}^{-}$, and $\mathrm{pH}$ ) at the depth of interest. To estimate the concentration of total dissolved $\mathrm{Mg}^{+2}$ in equilibrium with the sediment-pore water system at the depth of interest, we use the seawater concentration for this cation $(55.2 \mathrm{mM})$ as the starting point. Step 2 calculates the concentration of free $\mathrm{Mg}^{+2}$ using the program MINEQL and the pore water composition given in step 1. Step 3 calculates the $\mathbf{M g}^{+2}$ adsorbed to or released from solid surfaces, and the corresponding total dissolved $\mathrm{Mg}^{+2}$ in the system, using the free $\mathrm{Mg}^{+2}$ concentration obtained in step 2. Step 4 calculates the difference between the $\mathrm{Mg}^{12}$ concentration obtained in step 3 and the $\mathrm{Mg}^{+2}$ concentration entered in step 1 during the previous iteration. If this value is greater than $1 \%$ of the total dissolved $\mathrm{Mg}^{+2}$ (step 5), the process is repeated using the new total dissolved $\mathrm{Mg}^{+2}$ value calculated in step 3 . 
TABLE 4: The "reactive Mg" distribution in a hemipelagic pore water-solid sediment system during early diagenesis of organic matter. The multicomponent model includes complex formation, ion exchange with ammonium and surface adsomption-desorption reactions. $\mathrm{SCO}_{2}, \mathrm{NH}_{4}{ }^{+}$and $\mathrm{SO}_{4}^{-2}$ are calculated from the metabolite regeneration equations (1) and (2). The porosity and dry bulk density values are assumed constant at $\phi=80 \%$ and $p=0.5 \mathrm{~g} / \mathrm{cc}$. The empirical parameters for the surface reactions are those obtained for the DSDP Sile 479 whole-sediment sample; these are assumed to be characteristic of other hemipelagic sediments.

\begin{tabular}{|c|c|c|c|c|c|c|c|c|}
\hline \multicolumn{9}{|c|}{ Empirical parameters: } \\
\hline \multicolumn{4}{|c|}{$\begin{array}{l}\mathrm{CEC}=20.8 \mathrm{meq} / 1 \mathrm{Mg} \\
\mathrm{TEM}=8.0 \mathrm{meq} / 100 \mathrm{~g}\end{array}$} & \multicolumn{3}{|c|}{$\begin{array}{l}\alpha=54.1 \mathrm{mmol} / \text { iter } \\
\beta=1.50\end{array}$} & \multicolumn{2}{|c|}{$\mathrm{K}_{\text {cond }}=0.17 \mathrm{liter} / \mathrm{mol}$} \\
\hline $\begin{array}{l}\mathrm{xCO}_{2} \\
\mathrm{mM}\end{array}$ & $\begin{array}{l}\mathrm{NH}_{4}^{+} \\
\mathrm{mM}\end{array}$ & $\begin{array}{l}\mathrm{SO}_{4}^{-2} \\
\mathrm{mM}\end{array}$ & $\begin{array}{l}\Delta \mathrm{Mg}(\mathrm{Sfc})_{2} \\
\mathrm{meg} / 100 \mathrm{~g}\end{array}$ & ${ }_{m M}^{\left(\mathrm{Mg}^{+2}\right)_{\mathrm{F}}}$ & $\underset{\mathrm{mM}}{\mathrm{Mg}^{+2} \mathrm{~T}}$ & $\begin{array}{l}\left(\mathrm{Mg}\left(\mathrm{Sfc}_{2}\right)_{\mathrm{NH}}=0\right. \\
\mathrm{meq} / \mathrm{LOOg}\end{array}$ & $\begin{array}{l}\left(\mathrm{NH}_{4}(\mathrm{Sfc})\right)_{\mathrm{Mg}} \\
\mathrm{meq} / 100_{\mathrm{g}}\end{array}$ & $\begin{array}{l}{\left[\mathrm{Mg}\left(\mathrm{Sfc}_{2}\right]\right.} \\
\text { meqloog }\end{array}$ \\
\hline 2.8 & 0.26 & 28.5 & 0.05 & 49.0 & 55.1 & 7.99 & 0.01 & 7.98 \\
\hline 8.9 & 0.83 & 25.0 & 0.07 & 48.8 & 55.1 & 7.97 & 0.02 & 7.95 \\
\hline 24.7 & 2.33 & 15.0 & 0.09 & 48.5 & 55.4 & 7.95 & 0.05 & 7.90 \\
\hline 40.6 & 3.83 & 5.0 & 0.12 & 48.0 & 55.5 & 7.92 & 0.09 & 7.83 \\
\hline 48.6 & 4.58 & 0 & 0.13 & 47.9 & 55.7 & 7.91 & 0.10 & 7.80 \\
\hline 100 & 9.43 & 0 & 0.51 & 42.6 & 57.3 & 7.51 & 0.23 & 7.28 \\
\hline 150 & 14.1 & 0 & 0.92 & 38.0 & 58.1 & 7.12 & 0.36 & 6.76 \\
\hline 200 & 18.9 & 0 & 1.23 & 34.9 & 59.8 & 6.81 & 0.49 & 6.33 \\
\hline
\end{tabular}

result in considerable changes in the adsorption and ion exchange reactions involving magnesium. We have chosen a hemipelagic sediment sample from the Gulf of California (DSDP site 479) for an exemplary evaluation of the $\mathrm{Mg}^{+2}$ surface reactions during organic matter diagenesis. The empirical parameters for ion exchange behavior were those experimentally obtained and described in the preceding sections (Table 3). The metabolite composition is that obtained from Eqns. (1) and (2). Porosity and density were chosen to remain constant $(\rho=0.5 \mathrm{~g} / \mathrm{cc}$ and $\phi-80 \%)$. This allows us, in a very general way, to monitor the "reactive $\mathrm{Mg}^{+2}$ " distribution with increasing organic matter diagenesis. The results from the multi-component model calculations are summarized in Table 4.

Figure 10 shows the increase in the $\mathrm{Mg}^{+2}$ released from solid surfaces as a function of increasing $\mathrm{\Sigma CO}_{2}$ and $\mathrm{NH}_{4}^{+}$, and the corresponding consumption of $\mathrm{SO}_{4}^{-2}$. The amount of $\mathrm{Mg}^{+2}$ released from the solids is a function of the activity of the free ion, the composition of the pore water matrix (which includes the competition for exchange sites from the other seawater cations), and the surface properties of the solid. As the adsorption isotherm for this sample indicates (Fig. 6), the adsorbed $\mathrm{Mg}^{+2}$ will decrease with a decrease in the concentration of the free ion; furthermore, the free ion concentration will change as the concentrations of $\mathrm{\Sigma CO}_{2}$ and $\mathrm{SO}_{4}^{-2}$ vary with depth (Fig. 3). As a point of illustration, assuming no addition of $\mathrm{NH}_{4}^{+}$, the $\mathrm{Mg}^{+2}$ released by surface desorption due exclusively to ligand competition is shown by the black area in Fig. 10. This $\mathrm{Mg}^{+2}$ desorption is due to a decrease in the free $\mathrm{Mg}^{+2}$ with increasing $\mathrm{\Sigma CO}_{2}$ levels. The shaded area in Fig. 10 shows the $\mathrm{Mg}^{+2}$ released after including both the $\mathrm{Mg}^{+2}$ ammonium exchange and ligand competition.

The relative importance of these two mechanisms (ligand competition and ammonium exchange) for releasing $\mathrm{Mg}^{+2}$ from solid surfaces depends on the surface characteristics of the sediment, and on the $\mathrm{\Sigma CO}_{2}: \mathrm{NH}_{4}^{+}$regeneration ratio in the pore waters. This ratio may change because of differences in the C:N ratio of the organic matter substrate, by carbonate removal through precipitation of diagenetic carbonates, or by microbial carbonate consumption during methanogenesis. A decrease in this ratio will result in a higher amount of $\mathrm{Mg}^{+2}$ released by ammonium exchange relative to that desorbed in response to increased $\mathrm{Mg}^{+2} \cdot \mathrm{CO}_{3}^{-2}$ ion-pair formation in the pore water. Another obvious consequence of this multi-component equilibrium is that removal of $\mathrm{Mg}^{+2}$ from solution by dolomitization (or any other process involving permanent uptake of magnesium in a mineral lattice) will desorb more $\mathrm{Mg}^{+2}$ from the surrounding solid-phase exchangers. This may happen via both $\mathrm{NH}_{4}^{+}$exchange and equilibrium re-distribution between free and adsorbed $\mathrm{Mg}^{+2}$.

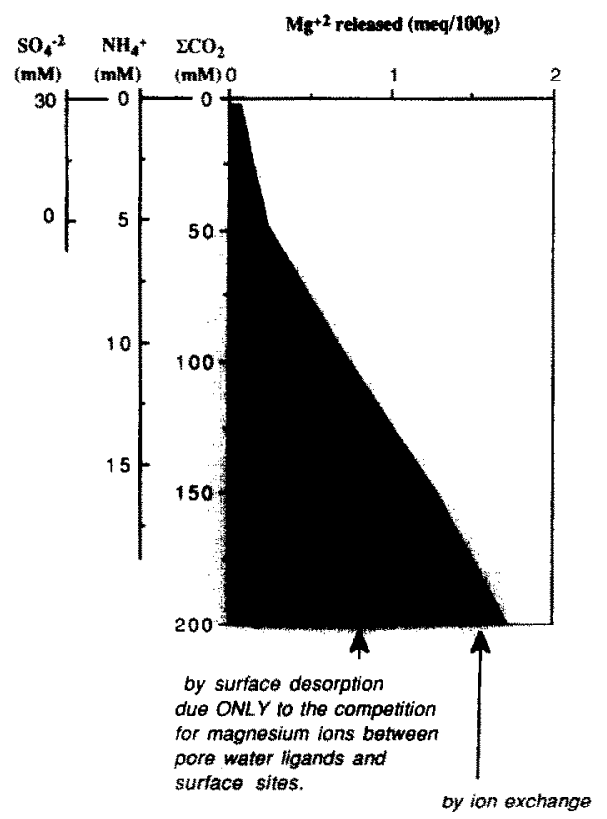

FiG. 10. $\mathrm{Mg}^{+2}$ released from the solid surfaces by ligand competition and ammonium exchange during diagenesis, as a function of metabolically induced changes in the concentration of $\mathrm{\Sigma CO}_{2}, \mathrm{SO}_{4}^{-2}$, and $\mathrm{NH}_{4}^{+}$. The metabolite ratios are those given by Eqns. (1) and (2), and the porosity and dry bulk density were assumed constant at $\phi$ $=80 \%$ and $\rho=0.5 \mathrm{~g} / \mathrm{cc}$. 
The effect of the diagenetic increase in $\mathrm{\Sigma CO}_{2}$ on the free $\mathrm{Mg}^{+2}$ concentration is compensated by the concurrent decrease in the sulfate ligand concentration (Fig. 3). Since the free $\mathrm{Mg}^{+2}$ concentration is buffered by these competing processes, we predict very small overall changes in the adsorbed $\mathrm{Mg}^{+2}$ within the sulfate reduction zone (Fig. 10). However, after $\mathrm{SO}_{4}^{-2}$ depletion, the adsorbed $\mathrm{Mg}^{+2}$ will decrease significantly as the $\mathrm{CO}_{3}^{-2}$ concentration continues to increase. This effect will be more pronounced in sulfate depleted systems, with high $\mathrm{\Sigma CO}_{2}$ and $\mathrm{NH}_{4}^{+}$concentrations such as in rapidly depositing continental margin sediments.

\section{Magnesium Distribution in Pore Fluids}

Maxima in the dissolved $\mathrm{Mg}^{+2}$ profiles have been reported in a number of anoxic sedimentary environments (COOK, 1974; GIESKES et al., 1982; SUESS et al., 1987). Since this excess $\mathbf{M g}^{+2}$ has only been observed at depth intervals of high ammonium levels, it was generally attributed to ion exchange with $\mathrm{NH}_{4}^{+}$. However, no quantitative evaluation of this proposed mechanism for $\mathrm{Mg}^{+2}$ release has been possible because of lack of values for the equilibrium constants of the solid exchanger reacting in a seawater medium. Previously we have shown this apparent positive anomaly of the pore water $\mathrm{Mg}^{+2}$ to be coincident with a decrease in the free ion content (Fig. 5). In addition, the decrease in free $\mathrm{Mg}^{+2}$ will also result in a desorption of $\mathrm{Mg}^{+2}$ according to the characteristic isotherms for each sediment (Fig. 6).

We now apply the multi-component model incorporating $\mathrm{Mg}^{+2}$ desorption by ligand competition and ammonium exchange to determine the relative extent of each mechanism in the solid-pore water system of the Gulf of California (DSDP Site 479), Bransfield Strait (Core 8101-278), and Peru margin (ODP Site 685). From the output of this model calculation we can evaluate the amount of $\mathrm{Mg}^{+2}$ released to the pore water at the given sediment density and porosity of each particular setting, and compare it to the respective $\mathbf{M g}^{+2}$ excess measured at these sites. The magnesium adsorbed onto sediment surfaces should decrease with depth due to the combination of ligand competition in the pore water and ammonium exchange reactions. Figure 11 shows this combined effect in the sediments of Bransfield Strait, Gulf of California, and Peru margin. The strongest depletion in adsorbed $\mathrm{Mg}^{+2}$ is calculated for the Peru margin sediment. This results from the extremely high concentrations of $\mathrm{\Sigma CO}_{2}$ and $\mathrm{NH}_{4}^{+}$in the pore waters (Fig. 5). In all cores, the $\mathbf{\Sigma} \mathrm{CO}_{2}$ concentration shows a decrease with depth (Fig. 5), probably related to the diagenetic formation of carbonate minerals. This is reflected in an increase in the adsorbed $\mathrm{Mg}^{+2}$ in the deeper sections of the cores, which is especially pronounced at the ODP site from the Peru margin.

The relative $\Sigma \mathrm{CO}_{2}: \mathrm{NH}_{4}^{+}$concentrations generated during organic matter diagenesis will determine the relative magnitude of the two mechanisms releasing $\mathrm{Mg}^{+2}$ from the solid surfaces. The pore waters in Bransfield Strait show a very high $\mathrm{C} / \mathrm{N}$ ratio (Fig. 1); thus, the $\mathrm{Mg}^{+2}$ release from the solid surfaces in this environment is predominantly driven by an increase in the $\mathrm{Mg}^{+2}$ bound to pore water ligands relative to the $\mathrm{Mg}^{+2}$ adsorbed to surface sites, i.e., a ligand competition mechanism, with ammonium exchange playing a smaller role near the top sections of the core (Fig. 12). As the dissolved carbonate is depleted relative to nitrogen, exchange with ammonium becomes more important in releasing $\mathrm{Mg}^{+2}$ from the sediment surface.

The other extreme case is represented by the ODP 685 sediments from the Peru margin. In this case, $\mathbf{\Sigma C O}_{2}$ is depleted relative to the $\mathrm{C} / \mathrm{N}$ Redfield ratio to begin with in the top sections of the hole (Fig. 1). $\Sigma \mathrm{CO}_{2}$ depletion increases with depth probably due to diagenetic carbonate mineral formation. This results in the release of $\mathrm{Mg}^{+2}$ from the surfaces being dominated by ammonium exchange. The ligand competition mechanism is almost insignificant in the deepest sections of the holc. In all cases, however, it is clcar that an explanation of the pore-water maxima in the dissolved $\mathrm{Mg}^{+2}$ profiles must consider both mechanisms simultaneously: ligand competition and ammonium exchange reactions.

To evaluate the validity of this model in predicting the dissolved $\mathrm{Mg}^{12}$ distributions in pore fluids, we have plotted the depth distribution of the predicted $\mathrm{Mg}^{+2}$ concentrations
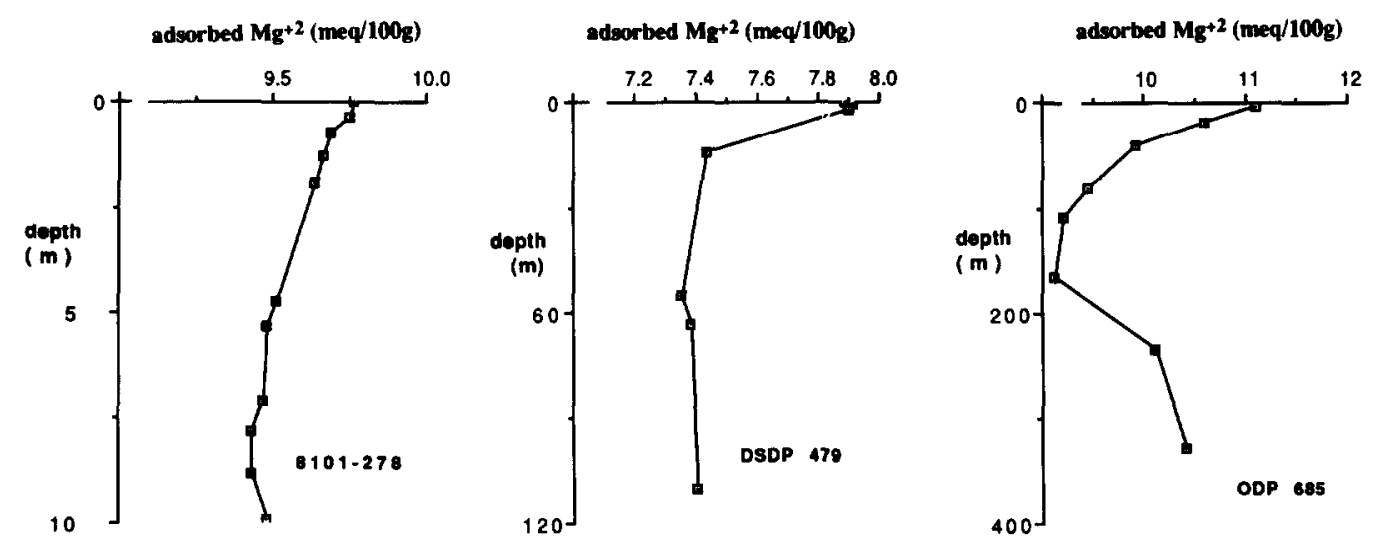

FIG. 11. Amount of $\mathrm{Mg}^{+2}$ adsorbed to sediment surfaces calculated by the multi-component model versus depth for the three selected hemipelagic sediments. 

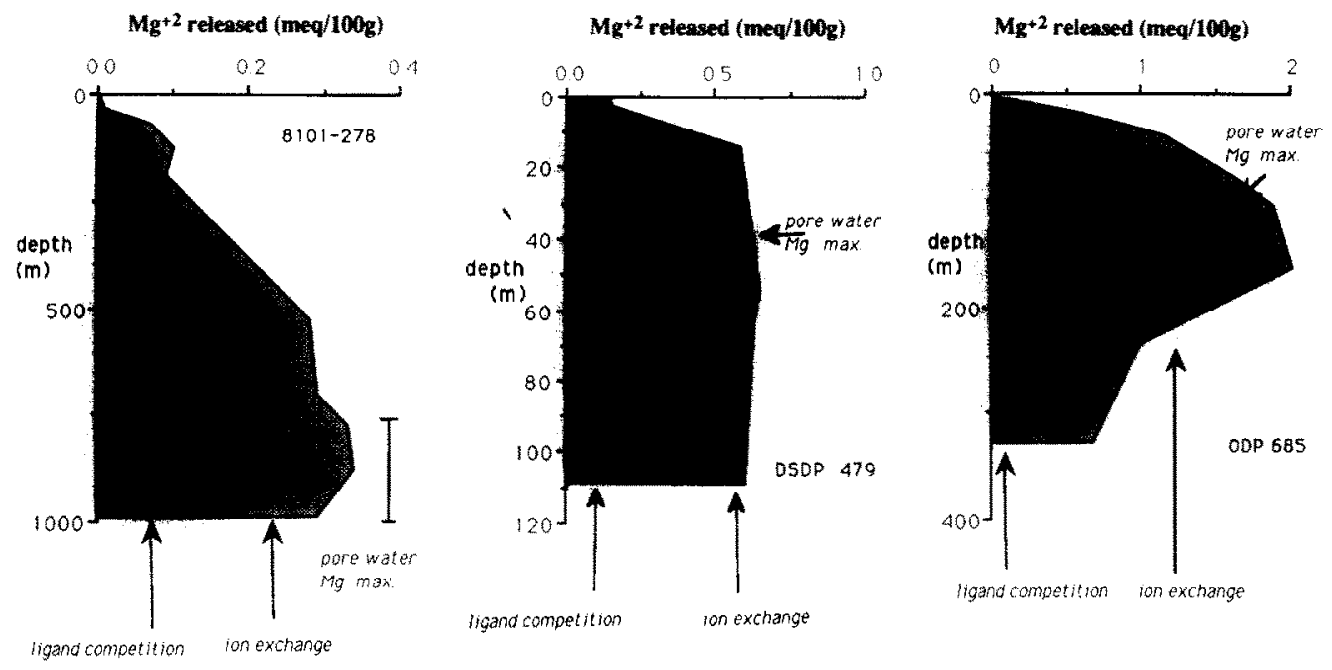

FIG. 12. $\mathrm{Mg}^{+2}$ released from sediment surfaces calculated by the multi-component model versus depth for the three selected hemipelagic sediments.

(closed symbols) and the actually measured values for this cation (open symbols) for the three model sediments used (Fig. 13). The $\mathrm{Mg}^{+2}$ released from the solid surfaces, as estimated by the multi-component model, only partially explains the excess of $\mathrm{Mg}^{+2}$ measured in the pore fluids of the sediments. In the Gulf of California and Peru margin sediments, the model predicts the magnesium distribution near the surface fairly well; however, at greater depths in the core the predicted $\mathrm{Mg}^{+2}$ excess is higher than that measured in the pore waters. This discrepancy results from $\mathrm{Mg}^{+2}$ removal from the pore water by the precipitation of diagenetic dolomite (KELTS and MCKENZIE, 1982; SUESS et al., 1987), a process not included in our model. In the Bransfield Strait there is an initial decrease in the amount of dissolved $\mathrm{Mg}^{+2}$ which cannot be explained by the model (Figs. 5 and 13), whereas at greater depths predicted and measured values agree very well.
An initial decease in the concentration of dissolved $\mathrm{Mg}^{+2}$ has been reported from various anoxic environments (SHOLKOVITZ, 1973; COOK, 1974) and has been explained in terms of an increase in the CEC of the sediments during early diagenesis (SHOLKovIrz, 1973). The removal of iron-oxide coatings under reducing conditions is thought to expose previously unavailable sites on the surface of the clays to the magnesium ions. In the model used so far, we have assumed a constant CEC throughout the sediment column, and therefore it fails to predict an initial $\mathrm{Mg}^{+2}$ depletion driven by diagenetic changes in the $\mathrm{CEC}$ of the sediment.

BisCHOFF et al. (1975) evaluated the $\mathrm{Mg}^{+2}$ uptake in strongly reducing environments caused by changes in the CEC of the sediments; however, as part of their experimental procedure these authors washed the sediments with distilled water prior to determining the adsorbed $\mathrm{Mg}^{+2}$. SAYLES and MANGELSDORF (1977) have since shown that altering the
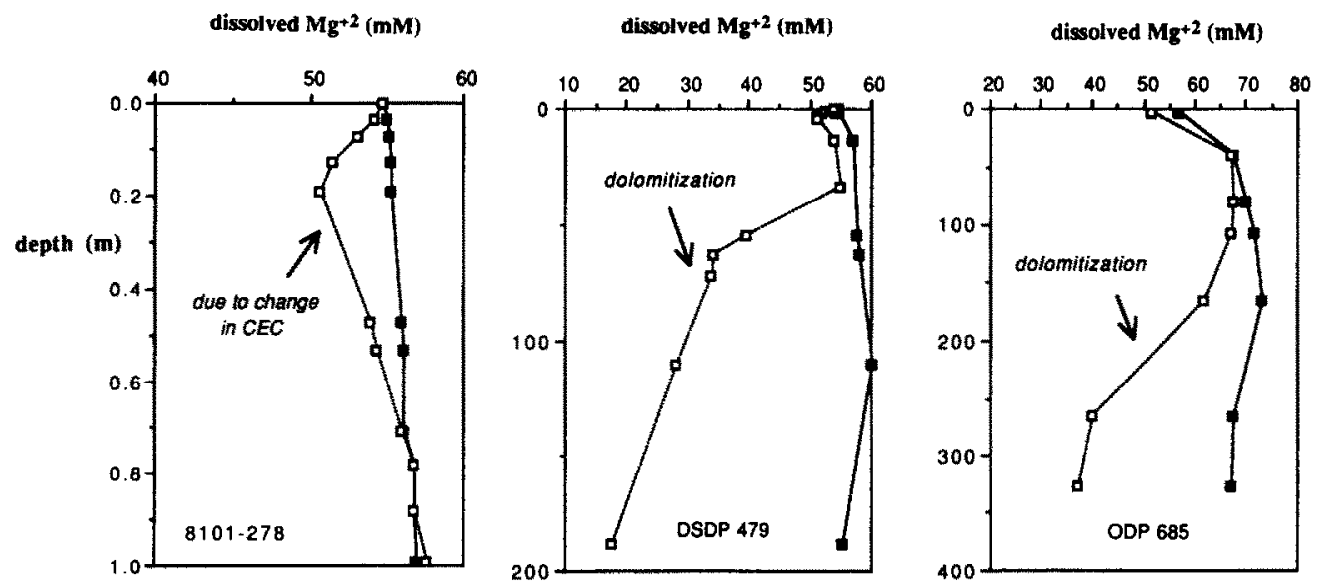

Fig. 13. Downcore profiles for predicted $\mathrm{Mg}^{+2}$ distributions using the multi-component model (closed symbols), assuming constant exchange capacity with depth, and actual measured values for this cation (open symbols) for the three hemipelagic sediments under study. 

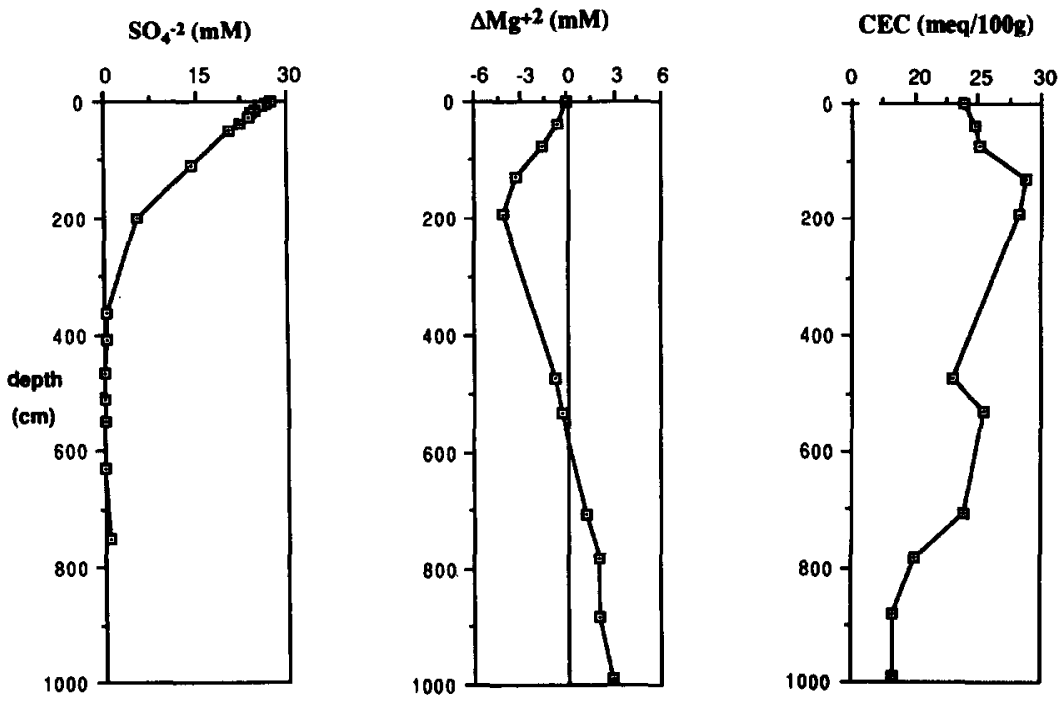

FIG. 14. Downcore distributions of dissolved $\mathrm{SO}_{4}^{-2}$, deviations of dissolved $\mathrm{Mg}^{+2}$ from the seawater value $\left[\mathrm{Mg}^{+2}\right]_{\mathrm{pw}}$, and cation exchange capacity (CEC) of the sediments in core 1327 from the Bransfield Strait basin.

composition of the interstitial matrix solution by dilution with distilled water results in a significant shift in the relative proportions of adsorbed ions on a solid exchanger. This shift is explained as a selective uptake of cations of higher valence relative to those of lower valence when the matrix composition changes. Our ${ }^{27} \mathrm{Mg}^{+2}$ radiotracer technique (VON BREYMANN et al., 1988) for determining the adsorbed $\mathrm{Mg}^{+2}$ on sediment surfaces in equilibrium with a seawater matrix now allows a more accurate estimation of the $\mathrm{Mg}^{+2}$ uptake in marine sediments.

To test the effect of these CEC changes on the dissolved $\mathrm{Mg}^{+2}$ distribution we modified the multi-component model, so that both the composition of the solution matrix (pore water) and the CEC of the solid phase (sediment) were al- lowed to vary with depth in the core. The measured downcore values of the CEC for the Bransfield Strait and Gulf of California sediments are shown in Figs. 14 and 15. The dissolved sulfate in the respective cores, also included in Figs. 14 and 15 , indicates a rapid removal by microbial sulfate reduction at shallow depths. The resulting hydrogen sulfide, plus the presence of iron sulfides, observed in the sediments of Bransfield Strait would support a mechanism proposed by SHOLKOVITz (1973) whereby the $\mathrm{Mg}^{+2}$ uptake from pore waters results from a diagenetic increase in the CEC via removal of iron-oxide coatings on clay surfaces. The oxidative decomposition of organic matter would also expose previously blocked sites in the surface of the clay where $\mathrm{Mg}^{+2}$ could be incorporated. The increase in CEC via oxidative removal of
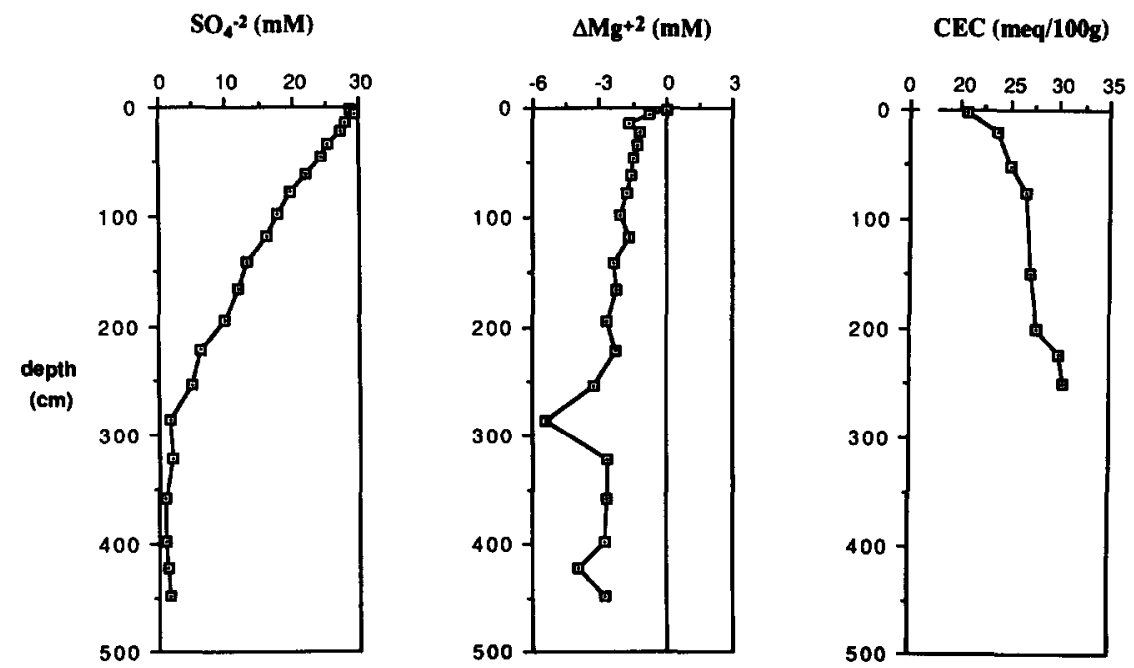

FIG. 15. Downcore distributions of dissolved $\mathrm{SO}_{4}^{-2}$, deviations of dissolved $\mathrm{Mg}^{+2}$ from the seawater value $\left[\mathrm{Mg}^{+2}\right]_{\mathrm{pw}}$, and cation exchange capacity (CEC) of the sediments in core E-17 from the Gulf of California. 

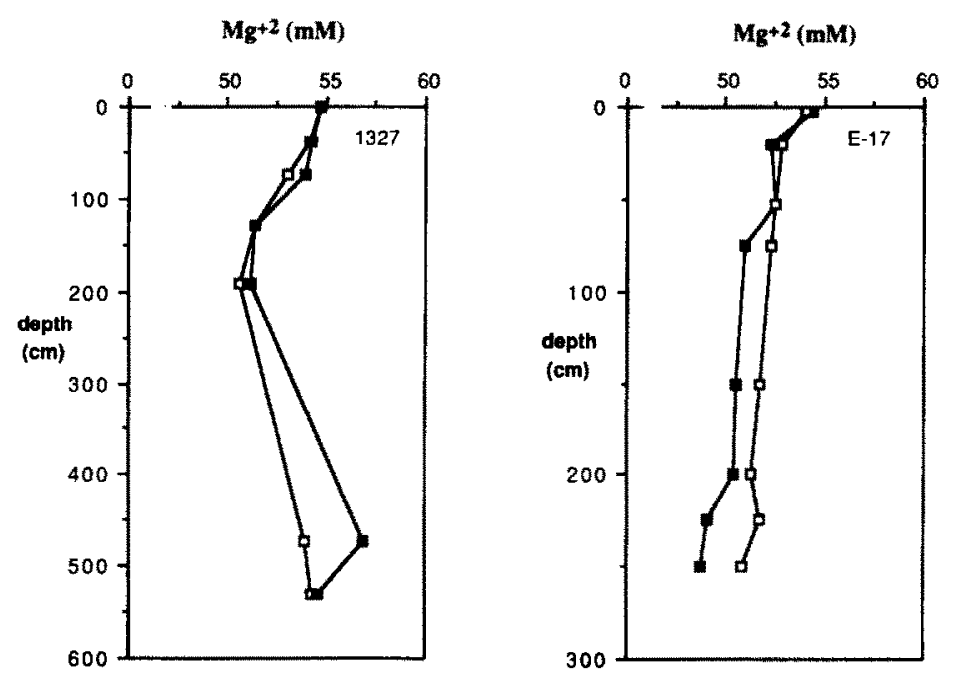

Fig. 16. Downcore distributions of dissolved $\mathrm{Mg}^{+2}$ measured in the pore water (open symbols) and predicted by the model that includes desorption of $\mathrm{Mg}^{+2}$ due to changes in the CEC of the sediments (closed symbols).

iron-oxide and/or organic coatings coincides with the largest deficit in the dissolved $\mathrm{Mg}^{+2}$, suggesting that the newly exposed sites do indeed remove cations from the pore fluids.

We have used actual pore water compositions and the measured CEC of the sediment at each depth to predict the dissolved $\mathrm{Mg}^{+2}$ concentrations. These are indicated by closed symbols in Fig. 16 and show good agreement with the measured $\mathrm{Mg}^{+2}$ values shown by the open symbols. Previously we had shown that ion-exchange and sorption/desorption reactions corresponding to changes in the free $\mathrm{Mg}^{+2}$ concentration may explain the excess of total dissolved $\mathrm{Mg}^{+2} \mathrm{ob}-$ served in various sedimentary environments. However, since that model assumed a constant CEC downcore, it failed to predict the $\mathrm{Mg}^{+2}$ deficit. Incorporating the diagenetic increase in the CEC of the sediments into the model (Fig. 16) now readily explains the negative anomaly in the dissolved magnesium profiles evident during the very early stages of anoxic diagenesis.

\section{Effect of Changes in Dissolved Calcium}

In the model discussed so far, we have not included the effects of other cations in the overall surface equilibrium balance. Among the major cations in pore fluids, calcium shows the largest deviations from seawater values; therefore, we have used the dissolved calcium in the three sites considered in the previous section (Fig. 17) to evaluate the effects that these changes have in the magnesium equilibria. For this purpose, we have added a third "box" to our model which includes the $\mathrm{Mg}^{+2}-\mathrm{Ca}^{+2}$ exchange, a reaction that was quantified by using the $\mathrm{NH}_{4}^{+}-\mathrm{Mg}^{+2}$ and $\mathrm{NH}_{4}^{+}-\mathrm{Ca}^{+2}$ equilibrium constants on montmorillonite calculated by LAUDELOT et al. (1967). We consider these to be appropriate as a first-order approximation since the value for $\mathrm{NH}_{4}^{+}-\mathrm{Mg}^{+2}$ exchange constant they report is consistent with the ones we determined experimentally (Table 3 ).

In all cases the model predicts that less magnesium will be
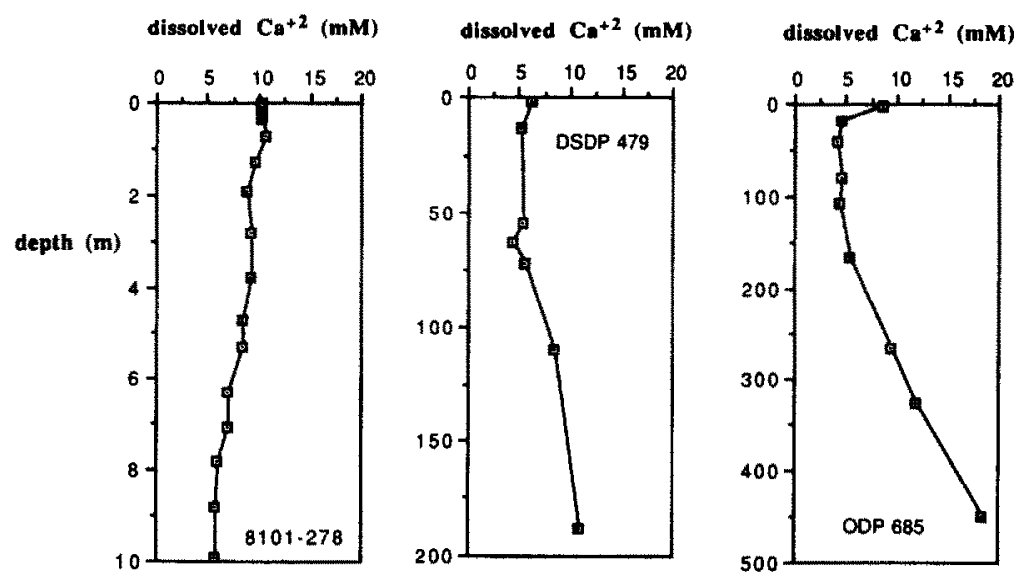

FiG. 17. Downcore distributions of total dissolved calcium in core 8108-278 (HAN, 1987), DSDP Site 479 (GIESKES et al., 1982), and ODP Site 685 (SUess et al., 1988). 

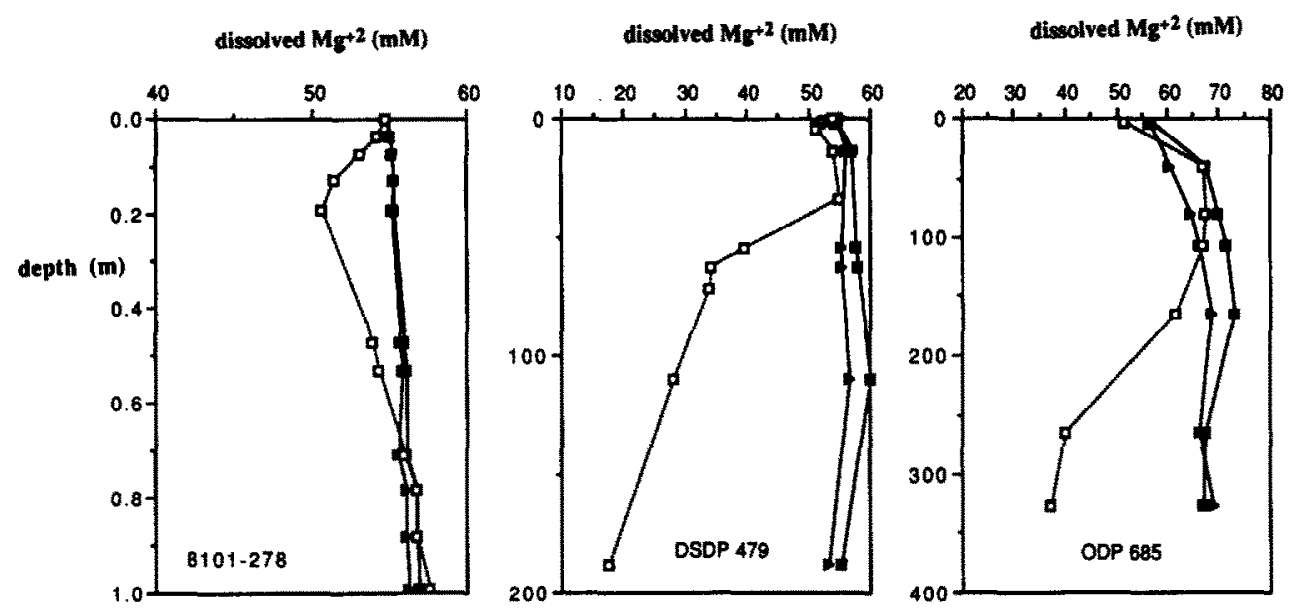

FIG. 18. Effect of calcium concentration changes on the magnesium profiles estimated by the multi-component model. The predicted $\mathrm{Mg}^{+2}$ distributions at a constant calcium value of $10 / \mathrm{mM}$ are shown by closed squares; the $\mathrm{Mg}^{+2}$ estimates using actual measured values for dissolved calcium are represented by closed triangles, and the $\mathbf{M g}^{+2}$ concentrations measured in the pore fluids are designated by open squares.

released into the pore fluids when the calcium concentration is lower than that of seawater (Fig. 18). This observation is not surprising since a re-equilibration of the surface of the solid with the composition of the dissolved phase results in desorption of calcium with a consequent increase in the magnesium adsorbed on the solid particles. To illustrate the magnitude of this effect Fig. 19 shows the change in the amount of magnesium adsorbed that results from the variations in dissolved calcium in the pore fluids at Site 685 .

Although the predicted concentration of $\mathrm{Mg}^{+2}$ in the pore fluids is lower than that estimated when no calcium-magnesium exchange was considered (Fig. 18), the predicted concentrations are of similar magnitude to those measured

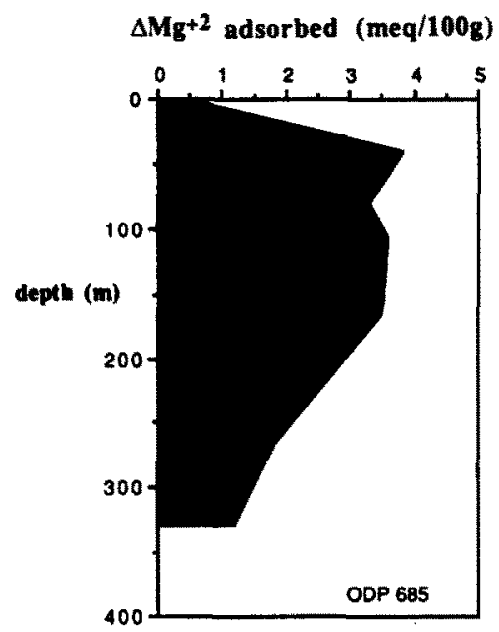

Fig. 19. Change in adsorbed $\mathrm{Mg}^{+2}$ versus depth at Site $685 \mathrm{cal}-$ culated by the multi-component model. The shaded area represents the estimated change in the $\mathrm{Mg}^{+2}$ bound to the surface of the solid when a constant calcium concentration is assumed; the dark area represents the change in the estimated $\mathrm{Mg}^{+2}$ adsorbed by incorporating in the model the changes in the calcium concentration measured in the pore water. in the pore fluids. Therefore, by including deviations in dissolved calcium concentration from seawater values in our model we do not change our main conclusion that magnesium desorption from the solid surfaces by ammonium exchange and ligand competition reactions results in a magnesium release to the pore water of a magnitude comparable to the values actually measured.

\section{SUMMARY}

The observed distributions of dissolved $\mathrm{Mg}^{+2}$ in the pore water of rapidly accumulating hemipelagic sediments (Bransfield Strait, Gulf of California, Peru margin) can be represented by the diagram shown in Fig. 20. These profiles typically show an initial decrease in the $\mathrm{Mg}^{+2}$ concentration relative to seawater, followed by an excess at mid-depths. We have shown that these two anomalics are the result of chem-

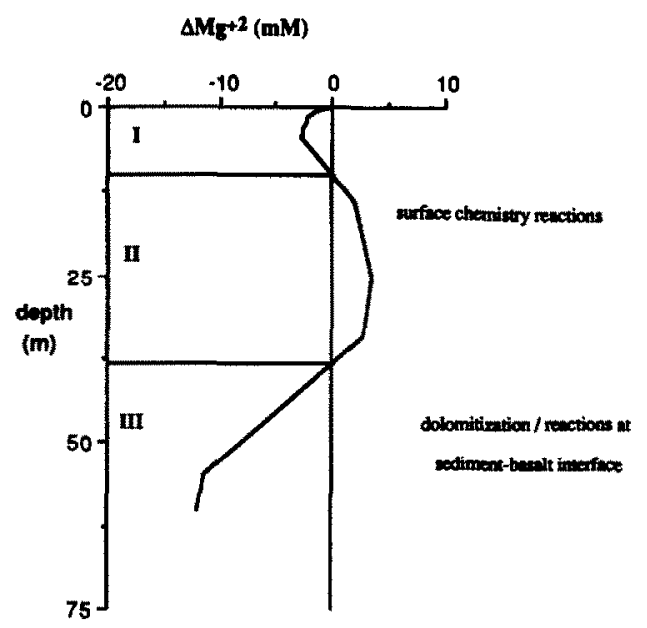

FIG. 20. Schematic profile for the dissolved magnesium in pore waters of rapidly accumulating pelagic sediments expressed as the deviation relative to seawater. 
ical reactions occurring at the surface of solid sediment particles, and are driven by changes in the composition of the pore water and in the surface characteristics of the solids. Other processes concurrent with the surface chemical reactions, particularly the diagenetic incorporation of magnesium into mineral lattices (dolomitization), arc responsible for the observed $\mathrm{Mg}^{+2}$ decrease at greater depths. These processes are responsible for the observed discrepancies in the profiles predicted by the model relative to the actual measured values.

The maximum in the dissolved profiles, observed almost ubiquitously in hemipelagic environments, results from the $\mathrm{Mg}^{+2}$ desorption from surface sites by the combined effect of ligand competition and displacement reactions. The $\mathrm{Mg}^{+2}$ minima which are not related to carbonate mineral diagenesis are related to surface reactions during early diagenesis. We have documented that the negative anomaly in the dissolved $\mathrm{Mg}^{+2}$ distribution in the Bransfield Strait and the Gulf of California regions is a result of an increase in the cation exchange capacity of these sediments.

Acknowledgments-This study was made possible by the unsupported research program of the OSU Radiation Center, which granted us access to the TRIGA reactor and to their laboratory facilities. We thank A. Ungerer, M. Conrady, T. V. Anderson, B. Carpenter, and A. Johnson for their valuable assistance during the radiotracer experiments. J. M. Gieskes kindly provided sediment samples from the Gulf of California DSDP Sites 478 and 479 . The computer program MINEQL was made available to us by J. C. Westall; $\mathbf{K}$. von Damm kindly provided computations on activity coefficients. Comments by J. M. Gieskes and F. L. Sayles greatly improved the manuscript. Additional support was provided by ONR grant N00014-84-C-0218, NSF grants DPP-8512395 and DPP-8743473, and ODP grant 7821464. We also gratefully acknowledge financial support from the Oregon State University Foundation.

\section{Editorial handling: S. E. Calvert}

\section{REFERENCES}

Atlas E., Culberson C., and Pytkowicz R. M. (1976) Phosphate association with $\mathrm{Na}, \mathrm{Ca}$ and $\mathrm{Mg}$ in seawater. Mar. Chem. 4, 243254.

BALZER W. (1984) Organic matter degradation and biogenic element cycling in a nearshore sediment (KIEL BIGHT). Limnol. Oceanogr. 29, 1231-1246.

BERNER R. A. (1980) Early Diagenesis: A Theoretical Approach. Princeton Series in Geochemistry, Princeton Univ. Press.

BisCHOFF J. L., ClANCY J. J., and BOOTH J. S. (1975) Magnesium removal in reducing marine sediments by cation exchange. Geochim. Cosmochim. Acta 39, 559-568.

BOATMAN C. D. and MURRAY J. W. (1982) Modeling exchangeable ammonia adsorption in marine sediments: Processes and controls of adsorption. Limnol. Oceanogr. 27, 99-1 10.

VON BREYMANN M. T. and SUESS E. (1988) Magnesium in the marine sedimentary environment: $\mathrm{Mg} / \mathrm{NH}_{4}$ ion exchange. Chem. Geol. 70, 359-371.

VoN BReyMaNN M. T., Ungerer C. A., and Suess E. (1988) Mg/ $\mathrm{NH}_{4}$ exchange on humic acid: Radiotracer technique for conditional exchange constants in a seawater matrix. Chem. Geol. 70, 349-357.

BRUMSACK H. J. and GIESKES J. M. ( 1983 ) Interstitial water tracemetal chemistry of laminated sediments from the Gulf of California, Mexico. Mar. Chem. 14, 89-106.

COOK P. J. (1974) Geochemistry and diagenesis of interstitial fluids and assoicated calcareous oozes, Deep Sea Drilling Project, Leg 27, Site 262, Timor Trough. Init. Rept. DSDP 27 pp. 463-480. US Government Printing Office, Washington, DC.
CuRray J. R. and MoORE D. G. (1982) Introduction to the Guaymas slope and laminated diatomite symposium. Init. Rept. DSDP 64 , pp. 1179-1183. US Government Printing Office, Washington, DC.

DREVER J. L. ( 1971a) Early diagenesis of clay minerals of Rio Ameca Basin, Mexico. J. Sediment. Petrol. 41, 982-994.

DREVER J. L. (197lb) Magnesium-iron replacement in clay minerals in anoxic marine sediments. Science 172, 134-136.

DYRSSEN D. and HANSSON I. (1973) Ionic medium effects in seawater-a comparison of acidity constants of carbonic acid and boric acid in sodium chloride and synthetic seawater, Mar. Chem. 1, 137-1149.

Garrels R. M. and Thomson M. E. ( 1962 ) A chemical model for seawater at $25^{\circ} \mathrm{C}$ and one atmosphere total pressure. Amer. J. Sci. 260, 57-66.

GIESKES J. M. ( 1975) Chemistry of interstitial waters of marine sediments. Ann. Rev. Earth Planet. Sci. 3, 433-453.

GiesKes J. M., ELDERFIELD H., LAWRENCE J. R., JOHNSON J., MEYERS B., and CAMPBELL A. (1982) Geochemistry of interstitial waters and sediments, Leg 64, Gulf of California. Init. Rept. DSDP 64, pp. 675-694. US Government Printing Office, Washington, DC.

HAN M. W. ( 1987 ) Dynamics and chemistry of pore fluids in marine sediments of different tectonic settings: Oregon subduction zone and Bransfield Strait extensional basin. Ph.D. dissertation, Oregon State University.

hartmann M., Muller P., Suess E., and van Der Weijden C. H. (1973) Oxidation of organic matter in recent marine sediments. Meteor. Forsch-Ergebnisse Reihe C 12, 77-86.

HOLLER O. (1985) Geotechnical properties of Antarctic deep sea sediments. Meteor Forsch.-Ergebnisse Reihe C. 39, 23-36.

JOHANSSON O. and WEDBORG M. (1979) Stability constants of phosphoric acid in seawater of $5-40 \%$ salinity and temperatures of 5-25 $5^{\circ}$ C. Mar. Chem. 8, 57-69.

KELTS K. and MCKENZIE J. A. ( 1982) Diagenetic dolomite formation in Quaternary anoxic diatomaceous muds. Init. Rept. DSDP 64 , Part 2, pp. 553-570. US Government Printing Office, Washington, DC.

KeSTNER D. R. and PytKowicz R. M. ( 1969) Sodium, magnesium, and calcium sulfate ion pairs in seawater at $25^{\circ} \mathrm{C}$. Limnol. Oceanogr. 14, 686-692.

Laudelot H., van Bladel R., Bolt G. H., and PaGe A. L. (1967) Thermodynamics of heterovalent cation exchange reactions in a montmorillonite clay. Trans. Faraday Soc. 64, 1477-1488.

MARTENS C. S., BERNER R. A., and RoSENFELD J. K. (1978) Interstitial water chemistry of anoxic Long Island Sound sediments. 2: Nutrient regeneration and phosphate removal. Limnol. Oceanogr. 23, 605-617.

Millero F. J. (1974) Seawater as a multicomponent electrolite solution, In The Sea. Vol. 5, Marine Chemistry (ed. E. D. GolDBERG), pp. 3-80. Wiley-Interscience.

Millero F. J. and SCHreiber D. R. (1982) Use of the ion pairing model to estimate activity coefficients of the ionic components of natural waters. Amer. J. Sci. 282, 1508-1540.

MOORE G. W. and GIESKES J. M. (1980) Interaction between sediment and interstitial water near the Japan Trench. Init. Rept. DSDP 56-57, pp. 1269-1275. US Government Printing Office, Washington, DC.

Morel F., MCDufF R. E., and Morgan J. J. (1976) Theory of interaction intensitics, buffer capacities, and $\mathrm{pH}$ stability in aqueous systems, with application to the $\mathrm{pH}$ of seawater and a heterogeneous model ocean system. Mar. Chem. 4, 1-28.

Murray J. W., Grundmanis V., and SMethie W. M. (1978) Interstitial water chemistry in the sediments of Saanich Inlet. Geochim. Cosmochim. Acta 42, 1011-1026.

PTIZER K. S. ( 1973 ) Thermodynamics of electrolytes. 1. Theoretical basis and general equations. J. Phys. Chem. 77, 268-277.

PYTKOWICZ R. M. and HAwLEY J. E. (1974) Bicarbonate and carbonate ion pairs and a model of seawater at $25^{\circ} \mathrm{C}$. Limnol. Oceanogr. 19, 223-234.

PYTKOWICZ R. M. and KeSTER D. R. (1969) Harned's rule behavior of $\mathrm{NaCl}-\mathrm{Na}_{2} \mathrm{SO}_{4}$ solutions explained by an ion association model. Amer. J. Sci. 267, 217-299.

Redfield A. C., KeTChum B. H., and Richards F. A. (1963) The 
influence of organisms in the composition of seawater. In The Sea, Vol. 2, (ed. M. N. HILL), pp. 26-77. J. Wiley \& Sons.

RICHARDS F. A. (1965) Dissolved gases other than carbon dioxide. In Chemical Oceanography (ed. J. P. RILEY and G. SkIRROW), Vol. 1, pp. 197-225. Academic Press, London.

ROSENFELD J. K. (1979) Ammonium absorption in nearshore anoxic sediments. Limnol. Oceanogr. 24, 356-364.

SAYLES F. L. and MANGELSDORF P. C., JR. (1977) The equilibration of clay minerals with seawater. Geochim. Cosmochim. Acta. 41, 951-960.

SHoL KovITz E. (1973) Interstitial water chemistry of the Santa Barbara Basin sediments. Geochim. Cosmochim. Acta. 37, 2043-2073.

STumm W. and MorGan J. J. (1981) Aquatic Chemistry: An Introduction Emphasizing Chemical Equilibria in Natural Waters, 2nd edn. J. Wiley \& Sons.

SUESS E. (1976) Nutrients near the depositional interface. In The Benthic Boundary Layer (ed. I. N. MCCAVE) pp. 57-77. Plenum Press, New York.

SuEss E. (1979) Mineral phases formed in anoxic sediments by microbial decomposition of organic matter. Geochim. Cosmochim. Acta. 43, 339-352.

SuEss E. (1981) Phosphate regeneration from sediments of the Peru continental margin by dissolution of fish debris. Geochim. Cosmochim. Acta. 45, 577-588.
Suess, E. Balzer W., Hesse K. F., Muller P. J., Ungerer C. A. and WEFER G. (1982) Calcium carbonate hexahydrate from organic-rich sediments of the Antarctic shelf: Precursors of Glendonites. Science 216, 1128-1131.

SuEsS E., KulM L. D., and KILLINGLEY J. S. (1987) Coastal upwelling and history of organic-rich mudstone deposition off Peru. In Marine Petroletum Source Rocks. (eds. J. Brooks and A. J. FLEET); Geol. Soc. Spec. Publ. 26, pp. 181-197.

SUESS E., voN HUENe R., et al. (1988) Proc. ODP. Init. Rept. (Pt. A) 112. College Station, TX (Ocean Drilling Program).

WestaLl J. C., ZaChary J. L., and Morel F. M. M. (1987) MINEQL. A computer program for the calculation of chemical equilibrium composition of aqueous systems. Report 86-01, Department of Chemistry, Oregon State University.

WhITICAR M. J. (1978) Relationships of interstitial gases and fluids during early diagenesis in some marine sediments. Ph.D. dissertation, University of Kiel, Germany.

WhITICAR M. J., SUESS E., and WeHNER H. (1985) Thermogenic hydrocarbons in surface sediments of the Bransfield Strait, Antarctic Peninsula. Nature 314, 87-90.

Whiticar M. J., FABER E., and SChOEll M. ( 1986) Biogenic methane formation in marine and freshwater environments: $\mathrm{CO}_{2}$ re duction vs. acetate fermentation-Isotope evidence. Geochim. Cosmochim. Acta. 50, 693-709. 